\title{
Ueber den Nystagmus und seine Aetiologie.
}

Eine vergleichend-klinische Studie

von

E. Raehlmann.

I. Ueber die Analogie des Nystagmus mit dem gewöhlichen Tremor.

Nach der Form der zitternden Bewegungen des Bulbus zerfällt der Nystagmus bekanntlich in zwei grosse Gruppen.

In der ersten Gruppe sind die Bewegungen rein undelirende, d. $h$. bei jeder einzelnen Schwingung geht die Bewegung von einem als fix gedachten Ruhepunkte nach beiden Seiten hin in gleicher Excursion und mit gleicher Geschwindigkeit vor sich.

Nach In- und Extensität variirt der Nystagmus zu verschiedenen Zeiten; im Allgemeinen pflegen die Excursionsweiten der Schwingungen um so kleiner zu sein, je schneller und hänfiger die Oscillationen sind.

Bei einer zweiten Gruppe sind die Bewegungen des Nystagmus nicht oscillirend, sondern erfolgen ruckweise, aber in rhythmischer Reihenfolge und zwar so, dass von einem bestimmten Ruhepunkte, beispielsweise von einer gegebenen Fixirstellung aus das Auge ruckweise nach einer bestimmten Seite gezogen wird. 
Der Nystagmus ist also in diesen Fällen ein rhythmisch-zuckender.

Die Richtung der Zuckungen ist eine wechselnde,
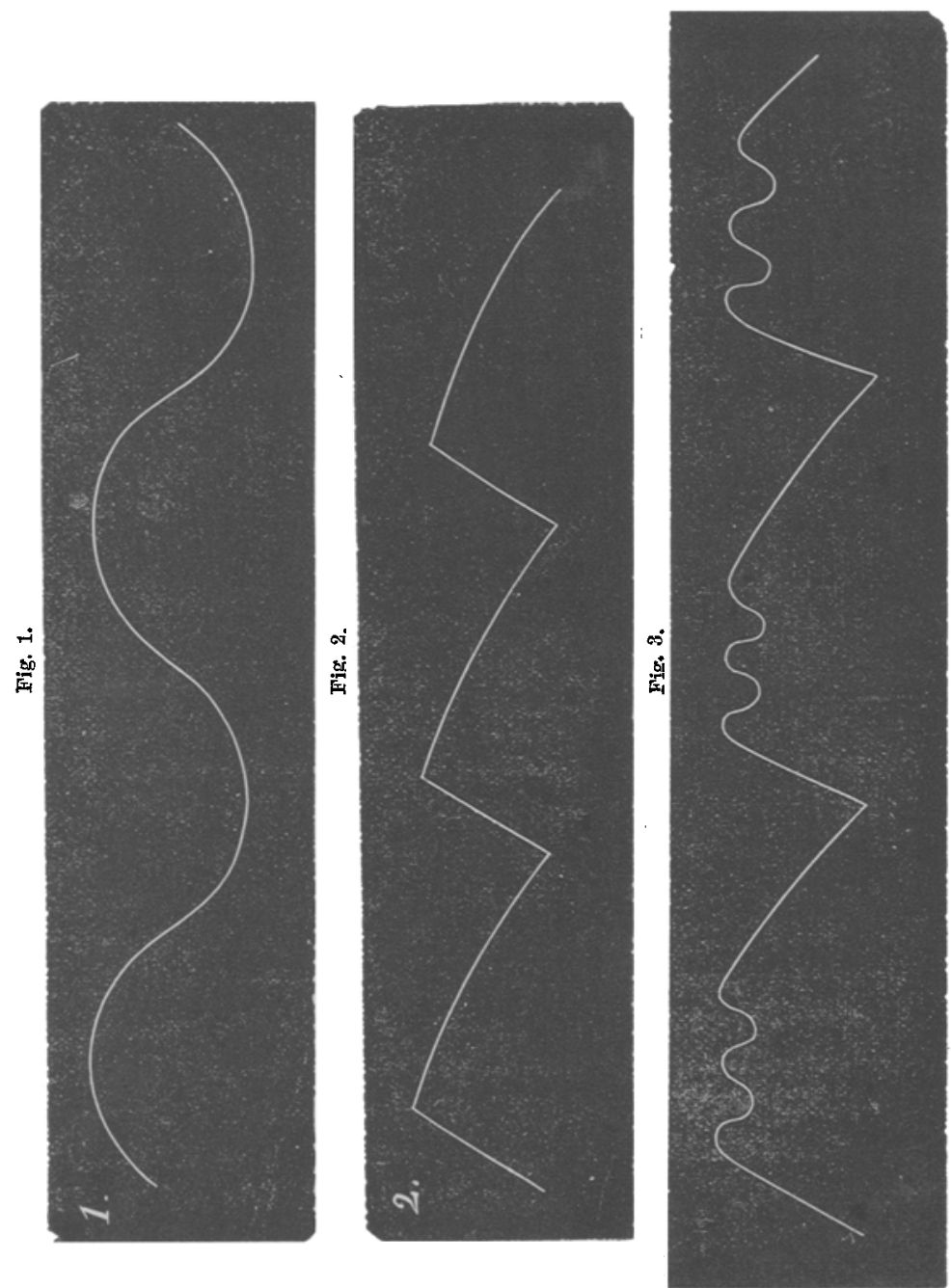

es können dieselben kürzere oder längere Zeit nach der einen, dann vorübergehend nach der anderen Richtung stattfinden. 
Dächte man sich auf der Mitte der Cornea einen Stift befestigt, welcher die Bewegungen des Bulbus mitmachte, so würde letzterer auf einer mit constanter Geschwindigkeit vorbeigeführten Fläche bei der ersten Folm die Carve 1, bei der zweiten Form die Curve 2 beschreiben. Häufig endlich findet sich der zuckende Nystagmus mit dem oscillirenden gepaart vor; gewöhnlich erfolgen dann nach einer zuckenden Bewegung mehrere Oscillationen und die Reihenfolge ist dann bisweilen eine so typische, dass eine in erwähnter Weise graphisch dargestellte Curve eine sehr regelmässige Gestalt haben würde. (Fig. 3.)

In der beschriebenen äusseren Erscheinung zeigt der Nystagmus eine grosse Aehnlichkeit mit gewöhnlichem Tremor.

Beim Tremor der Gliedmassen, z. B. der Hände, sind ebenfalls oscillirende Bewegungen der Finger etc. vorhanden, die nach demselben Typus, wie der Nystagmus vor sich gehen.

In der älteren und neueren klinisehen Literatur finden wir mehrfach den Nystagmus als Tremorform definirt, und erst einseitige Bestrebungen der Ophthalmologen haben etwas besonderes aus ibm machen wollen.

Nach Hasse*) kommt der Tremor des Auges als Nystag. mus und Hippus allein ansgebildet vor, dagegen wird bei allgemeinem Tremor nur selten Nystagmus angetroffen.

Anch Rosenthal ${ }^{*}$ ) definirt den Nystagmus als den Tremor des Auges, „vom Tremor kann nur ein Theil der Gliedmassen, häufiger die oberen als die unteren ergriffen werden, ebenso die Nacken- und Kopfmuskeln oder die Gesichts - Unterkiefer und Zungenmuskeln; bisweilen sind blos zitternde Bewegungen der Augenmuskeln in Form des Nystagmus vorhanden."

*) Hasse (Virchow's Handbuch der speciellen Pathologie und Therapie, IV. Bd., 2. Auflage, pag. 321.) Erlangen, 1869.

**) Rosenthal (Nervenkrankheiten, pag. 564 u. ff.) 
Aber abgesehen von der äusseren Aehnlichkeit, welche nicht $\mathrm{zu}$ verkennen ist, wird die Analogie noch grösser, wenn wir die Bedingungen erforschen, welchen der Tremor sowohl als der Nystagmus gemeinsam unterliegen.

Zunächst ist hier der Einfluss der Gemüthsbewegungen zu erwähnen, welche, wie den Grad eines jeden Tremor, so auch den des Nystagmus bedeutend verändern.

Bei psychischer Aufregung erreicht der Nystagmus eine ungewöhnliche Höhe. In der Angst, bei plötzlichem Erschrecken etc. können bedeutende Bewegungsexcursionen beobachtet werden und wie der Tremor (Rosenthal)*), so kann auch der Nystagmus nach gewissen sensoriellen Einwirkungen vorübergehend auftreten. Er fehit ebenso wie der-Tremor im natürlichen Schlafe. Gleichwie der Tremor der Extremitäten bedeutend verstärkt gefunden wird, nach heftigen körperlichen Anstrengungen, sowie bei Zuständen allgemeiner Sehwäche und Erschöpfung, so findet man auch den Grad des Nystagmus bei solchen Zuständen bedeutend stärker, so dass die Oscillationen oder Zuckungen der Augen, wenn sie für gewöhnlich kaum wahrnehmbar sind, in solchen Zuständen deutlich hervortreten und auch der Umgebung des Kranken besonders aufzufallen pflegen.

Wie der Tremor, ganz so verhält sich auch der Nystagmus gegenüber der Wirkung des Alkohols; nach Genuss einer bestimmten Quantität wird auch der Nystagmus anfangs geringer, um später stärker wieder hervorzutreten (Graefe $\left.{ }^{* *}\right)$, Drausart***).

*) Rosenthal (1. c., pag. 565).

**) Graefe, A. Motilitätsstörungen (Handbach von Graefe u. Sremisch. Bd. VI. 1.)

***) Drausart. (Aunales d'oculist, Tom, LXXVIII., p. 110.1877.) 
Wir wissen endlicb, dass der Tremor der Extremitäten bei Vornahme gewisser Bewegungen stärker hervortritt, bei anderen Bewegungen derselben Organe sich mehr verliert; ganz dasselbe ist beim Nystagmus der Fall. Bei gewissen Augenbewegungen kann er stärker, bei anderen geringer werden, bei gewissen Stellungen des Bulbus hört er bisweilen ganz auf.

Und wie das Zittern der Gliedmassen bisweilen vollständig aufhört, wenn ein bedeutender Willensimpuls zu einer bestimmten Bewegung oder Bewegungsleistung vorliegt, wie z. B. das Zittern der Hand und der ausgestreckten Finger aufhört, oder in andercn Fällen sich auch verstärkt, wenn ein Gegenstand fest angefasst gehalten wird, so zeigt auch der Nystagmus eine bereits oft constatirte Abhängigkeit von dem zweckbewussten Sehakte, insofern, als beim Bestreben, einen Gegenstand scharf zu fixiren, der Nystagmus augenfällig seinen Charakter wechselt, bei einzeinen Patienten sich verringert resp. aufhört, bei anderen sich verstärkt.

\section{Aetiologie des Nystagmus.}

A. Ueber die neuropathische Natur des Nystagmus.

Wenn wir die Analogie des Nystagmus als des Augenzitterns mit dem Tremor schlechthin constatirt haben, und ich glaube, die Analogie könnte kaum vollständiger gewünscht werden, so wird auch die Frage $\mathrm{zu}$ erörtern sein, ob der Nystagmus sowohl wie das Zittern anderer Körpertheile auch hinsichtlich ibrer Ursache gemeinsam Uebereinstimmendes haben.

Schon van Swieten*) hat für den Tremor eine CentralUrsache postulirt. Nach ihm ist das Zittern, welches im Ruhezustande besteht, die Folge einer intermittirenden rhythmischen

*) van Swieten (Commentaria A. II., pag. 167. Paris, 1771). 
Erregung der Nervencentren, und das Zittern bei gewoliten Bewegungen die Folge einer Unzulänglichkeit des nervösen Fluidums.

Später hat Volkmann*) eine Centralstätte für die zitternden Bewegungen im Rückenmark gefunden, indem er nachwiess, dass am geköpften Thier Zittern auftritt, wenn dureh das Rückenmark ein schwacher Strom eines elektro - magnetischen Apparates geleitet wird.

In Uebereinstimmung hiermit findet Eulenburg**), dass die Annahme des spinalen Tremor an Wahrscheinlichkeit gewinne durch das Verschontbleiben der von den motorischen Hirnnerven versorgten Muskeln anderer Tremorformen, bei welchen die mimischen Gesichtsmuskeln, Kaumuskeln, Zungenmuskeln etc. participiren, sind dagegen nach E. wahrscheinlich cerebraler Natur.

Der Nystagmus findet sich bei allgemeinem Tremor selten, mit Ausuahme des ataktischen und des bei disseminirter Sclerose vorkommenđen. Dagegen findet sich, wie wir weiter unten sehen werden, der Nystagmus recht häufig neben Zittern des Kopfes, der mimischen Gesichts-, der Zungenmuskeln etc.; es trifft daher auch für den Nystagmus obige Bemerkung Eulenburg's über die centrale Natur vollständig zu.

Das gewöhnliche Zittern schliesst sich nach Freusberg***) an active Zustände und Thätigkeitsveränderungen des Blutgefäss - Apparates. Auch die Abhängigkeit des Nystagmus von Circulationsveränderungen ist bekannt; daher die Steigerung desselben bei Frost, Kälte etc., vielleicht ist die Einwirkung der Gemüthsbewegungen überhaupt auf Veränderungen des vasomotorischen Apparates zurïckzufübren.

*) A. W. Volkmann. (Nervenphysiologie in B. Wagner's Handwörterbuch der Physiologie, pag. 488).

**k) Eulenburg. (Theorie des Tremor, Handbuch der Krankheiten des Nervensystems, pag. 373).

***) Freusberg, A. (Archiv für Psychiatrie, Bd. VI, p. 62). 
Wenn Böhm*) behauptet, dass der Nystagmus peripherer Natur sei und sich auf die Funktionsstörung eines Augenmuskels zurückführen lasse, so entspricht dieser Erklärungsversuch einer höchst einseitigen Auffassung und Auslegung eines Symptoms von ganz allgemeiner Bedeutung, dessen vielfache Analogien dabei vollständig übersehen werden, und doch hat die Böhmsche Theorie trotz der Widerlegung durch Nakon $\mathrm{z}^{* * *}$ ) und $\mathrm{Kugel}{ }^{* * *}$ ) in der Literatur dauernde Berücksichtigung gefunden und der neueste Forscher auf dem fraglichen Gebiete A. Graefe†), welcher in höchst umfassender Weise das Krankheitsbild des Nystagmus gezeichnet, glaubt für bestimmte Formen an die Bedeutung peripherer Muskeldispositionen festhalten zu müssen.

Das eigentliche Zittern charakterisirt sich gegenüber dem sogen. fibrillären Zittern durch die gleichzeitig zusammenwirkende Thätigkeit aller Theile der ergriffenen Muskelgruppen, aus welcher eine geringe Bewegungsleistung resultirt, dieses kann nur bewirkt werden durch einen alle betheiligten Muskeln treffenden Impuls, der im Organismus nur vom Centralorgane ausgehen kann. (Freusberg) + ).

Nach Nothnagel $\dagger \dagger \dagger$ ) beruhen klonische Zuckungen beim Frosch auf abwechselnder Anspannung antagonistischer Muskelgruppen und diese Erklärung würde für den gewöhnlichen. oscillirenden Nystagmus ganz gut passen.

*) Böhm. (Der Nystagmus und dessen Heilung. Berlin 1877.

**) Nakonz. (Graefe's Archiv, Bd. V. 1., pag. 37).

***) Kugel. (Archiv für Ophth. Bd. XIII. 2, pag. 413).

1) A. Graefe. (Motilitätsstörungen, pag. 229).

t十) Freusberg, l. c.

†t+) Nothnagel. (Virchow's Archiv, Bd. XLIV. Zur Lehre vom Klonischen Krampf). 
Dagegen würde für die Form des zuckenden Nystagmus die Erklärung weit eher zutreffen, welche Romberg*) für das gewöhnliche Zittern giebt. - Nach Romberg entsteht Zittern durch stossweise rasch sich folgende Contraction gewisser Muskeln, mit nur passiver Betheiligung ihrer Antagonisten. (Romberg beruft sich auf das oben erwähnte Experiment Volkmann's).

Es würde gemäss dieser Erklärung beim zuckenden Nystagmus eine continuirliche Reihe rhythmisch unterbrochener Innervationen rom Centralorgane aus bestimmte Augenmuskeln treffen und die Zuckungen dieser letzteren veranlassen, und während der Intermission würde ein Ausgleich der Muskelspannung die natürliche Ruhelage des Auges wieder herstellen und diesem Ausgleichsbestreben würde die langsam rückläufige Bewegung beim zuckenden Nystagmus entsprechen.

B. Besonderes über einige wichtige Complicationen und deren Bedeutung für die neuropathische Natur des Nystagmus.

1. Ueber Nystagmus neben Missbildungen des Kopfes und der Auges.

Der Nystagmus findet sich sehr häufig neben Missbildungen des Körpers überhaupt und insbesondere der Kopfknochen, mit Microcephalus etc. Er besteht daher relativ oft neben jenen bei Kopfmissbildungen vorkommenden psychischen Defecten, namentlich bei den verschiedenen Formen des Schwachsinns, des Blödsinns und des Idiotismus.

Ich habe bei Untersuchung der Kranken in liesiger

*) Romberg. (Lehrbuch der Nervenkrankheiten, 3, Auflage, pag. 711). 
psychiatrischer Anstalt im Verlaufe der letzten Jahre relativ oft Nystagmus gesehen und meistens mit Kopfmissbildungen resp. Idiotismus gepaart. In Stephansfeld, der Irrenanstalt für Elsass - Lothringen, welche gegenwärtig ca. 800 Kranke besitzt, konnte ich bei flüchtigem Durchgehen durch die Räume unter 5 Fällen von Nys. tagmus 3 Fälle bei Idioten constatiren, eine Zahl, welche nur ein minimales Verhältniss ausdrückt, wenn man bedenkt, dass bei flüchtigem Durchgehen durch eine so stark besetzte Anstalt manche Fälle entgehen können. Jedenfalls ist ein solehes Verhältniss gegenüber den von Desmarres und Wecker angegebenen Zahlen ziemlich auffallend. Nach Gadaud*) kommen nämlich in der Wecker'schen Klinik durchschnittlich auf 950 Augenkranke 2 Fälle von Nystagmus und nach Desmarres kommen 3 Nystagmus Fälle auf 1000 Augenkranke.

Dann findet man den Nystagmus oft neben Missbildungen des Auges selbst, welche ihrerseits von den Kopfmissbildungen abhängig sein, oder doch mit ihnen im Zusammenhang stehen können.

Für die aus frühester Kindhcit stammenden hohen Grade von Myopie und Astigmatismus, bei denen bekanntlich sehr häufig auch Nystagmus beobachtet wird, ist die Abhängigkeit von Kopfinissbildung durch die Untersuchungen von Donders und Wecker festgestellt worden. - Bekannt ist das häufige Vorkommen des Nystagmus bei Microphthalmus, Colobom der Iris, Chorioidea und anderen Hemmungsbildungen des Auges, forner bei Schichtstaar, Cataracta centrales, bei Corticalstaaren etc.

$$
\text { Beobachtung } 1 \text {, }
$$

[Nystagmus abhängig von Affecten. Zittern des Kopfes, der Hände etc.]

V. G., Pfründner des hiesigen Spitals, 45 Jahre alt -

*) Gadaud, A. v. E. Etude sur le Nystagmus. (Thèse de Paris 1869). 
Schwachsinn mittleren Grades, hat Lesen und Schreiben gelernt, complicirte Bogriffe foblen, ist zum Arbeiten nicht zu gebrauchen, ist schwatzhaft, lacht beständig, bettelt etc. Verkrüppelter Körper, kann wegen Contracturen an dor linken Seite sich nur an Krücken bewegen. Kopf klein. Umfang $50 \mathrm{Cm}$., Frouto - occipital - Durchmesser (Längsdurehmesser) $16,5 \mathrm{Cm}$., grösster Querdurchmesser $15,0 \mathrm{Cm}$., Mento-vecipitalDurchmesser $20 \mathrm{Cm}$., Tremor des Kopfes mässigen Grades (Kopfwankeln), ausserdem Tremor der Hände, der Zunge ete. Beiderseits Microphthalmos, Colobom der Iris, auch der Chorioidea, dessen obere den Sehnervenquerschnitt noch umfassende Grenze troṭz vorhandener geschrumpfter Cataract noch $\mathrm{zu}$ sehen ist.

Die Sehschärfe des linken Auges bis auf Wahrnehmung von Handbewegungen herabgesetzt. Rechts werden Finger in $14^{\prime}$ Entfernung gezählt und grössere Schrift (J. 4) mit Convexgläsern in nächster Nähe gelesen, oscilirender Nystagmus sehr geringen Grades für gewöbnlich kaum bemerkbar, in Zuständen von Affect sowie nach Alkoholgenuss deutlicher hervortretend. Der Nystagmus wird von Blickrichtungen nicht beeinflusst und steht in teinem Verbältniss zu den zitternden Kopfbewegungen, da die letzteren rom Nystagmus unabhängig variiren.

Es ist nun eine ebenfalls bekannte Thatsache, dass fast immer neben solchen Missbildungen der Kopfknochen, neben diesen Missbildungen am Auge und neben dem Nystagmus psychische Defecte oder nervöse Störungen existiren und es liegt deshalb nahe, diesen letzteren eine ursächliche Bedeutung für den Nystagmus zuzuschreiben.

Ganz in diesem Sinne führt bereits $\mathrm{Nak}$ onz*) die erwähnten Missbildungen des Auges und den nebenhergehenden Nystagmus auf eine gemeinsame centrale Ursache zurück.

Nystagmus kommt nun ferner ungemein häufig vor bei der mit Pigmentdegenerationen, Pigmentmangel oder

*) Nakouz, l. c., pag. 45 . 
Pigmentneabildung, in der Chorioidea einhergehenden Affectionen, zunächst beim Albinismus und dann bei jener Erkrankungsgruppe, deren vorzüglichsten Repräsentanten die sog. retinitis pigmentosa vorstellt.

Für die retinitis pigmentosa, insbesondere die sogen. atypischen Formen mit frühzeitiger Herabsetzung des centralen Sehvermögens und weniger hochgradiger Einschränkung des Gesichtsfeldes und den so häufig nebenhergehenden Nystagmus ist in vielen Fillen die erbliche Natur erwiesen, sowie das Vorkommen neben anderweitigen Missbildungen neben Microcephalos und Fehlern im Bereiche des Nervensystems (Leber, Horing*).

Unter 30 Kranken fand Liebreich**) 14 Taubstumme***), 3 Idioten. Nach demselben Forscher findet sich in der Hälfte der Falle eine Blutsverwandtschaft der Eltern als Ursache vor. Lober konnte die Blutsverwandtsehaft der Eltern nur in 27,3 pCt. der Fälle constatiren.

Für die Frage nach dem Ursprunge des Nystagmus, der bei retin. pigm. sich findet, sind die Complicationen mit Krankheiten und Defecten des Centralnervensystems besonders wichtig.

\section{Beobachtung 2.}

[Passagerer Nystagmus bei Chorioidealerkrankung und PigmentNeubildung abhängig von der Beleuchtung.]

St. Charles, 46 Jahre alt, aus Strassburg, leidet an Chorioiditis dissem, mit sogenannter Pigmentinfiltration in die Netzhaut. Augen-Medien sind klar! Em. Sehvermögen stark herabgesetzt. (Es werden nur bis 6' Abstand Finger gezählt). Gesichtsfeld nicht bedentend eingeongt, Farbenempfindung normal. - Sehr kleiner brachycephal gebauter Schädel mit ungemein flacher Stirn - sonst körperlich gat entwickelt.

*) Leber. (Die Krankheiten der Netzhaut und des Sehnerven. Graefe u. Saemisch, Bd. V., pag. 654).

Horing. (Zehender's Monatsblätter für Augenheilkunde. Ir., pag. 237).

**) Li ebreich, R. (Abkunft aus Ehen unter Blutsverwandtschaft als Grund von retinitis pigmentosa. Deutsche Klinik, 6).

***) Stoer. (Zehender's Monatsbl. III., pag. 23. Pedraglia (ebenda, pag. 114). 
Für gewöhnlich bei der Ruhelage sowohl als bei Bewegungen der Augen kein Nystagmus. Derselbe tritt jedoch vorübergehend auf in Form horizontaler Oscillationen, wenn der Patient anfgeregt wird oder nach Anstrengungen ermüdet. Bei der ophthalmoskopischen Belouchtung (der Patient wurde $z$ op ophthalmoskopischen Demonstrationen verwandt) verharren anfangs die Augen ruhig, nach kurzer Zeit beginnen die Oseillationen und steigern sieh immer mehr, so dass die Untersuchung sehr schwierig wird; sie dauern dann eine Weile an, auch wenn die Untersuchung unterbrochen wird, bis sie allmälig wieder verschwinden. Der Nystagmus zeigt während seines Bestehens keine Abhängigkeit ron Fixationsbedingungen oder Blickrichtungen, er scheint nur beim Blick nach oben an Intensităt etwas abzunehmen.

2. Ueberdas nebendem Nystagmus vorkommende Kopfzittern.

Dass neben dem Nystagmus sehr oft Kopfwackeln beobachtet wird, ist eine schon lange bekannte Thatsache. Man hat seitens der Ophthalmologen nach dem Vorgange von Boehm*) und Stellwag**) fast allgemein angenommen, dass dieses Kopfwackeln in genau antagonistischem Verhältnisse zu den Nystagmusbewegungen auftritt, so dass die Augenbewegungen genau compensirt werden und in Folge dessen die Fixationsbedingungen beim Sehakt ganz den normalen ähnlich blieben.

Dass eine solche Anschaung, ursprünglich wohl nur aus dem Bestreben hervorgegangen, den Mangel der Wahrnehmung von Scheinbewegung bei den meisten Kranken einigermassen physiologisch zu erklären, gänz-

*) Boehm, D. Ludwig. (Der Nystagmus und dessen Heilung, pag. 69). Berlin, 1857.

**) Stellwag von Carion. Lehrbuch der praktischen Augenheilkunde, pag. 984. Wien, 1870. 
lich unhaltbar ist, wird durch genaue Beobachtung eines jeden Falles bewiesen.

Es ist nämlich sehr leicht nachzuweisen, dass das Zittern des Kopfes gauz unabhängig von dem Zittern der Augen nach In- und Extensität variirt. Von 60 bis 80 Oscillationen wechselt die Häufigkeit der Augenbewegungen bis $\mathrm{zu} 150$ bis 200 in der Minute, die Anzahl der Kopfbewegungen kann ganz entgegengesetzt wechseln.

Bisweilen genügen einige rasche Kopfdrehungen um die horizontale Axe, rasch "wechselnde seitliche Neigungen, welche man vom Patienten vornehmen lässt, um das Kopfzittern bedeutend zu steigern, ohne dass der Grad des Nystagmus eine entsprechende Aenderung zeigte.

Noch besser vermögen jene Fälle das Verhältniss beider Bewegungen zu einander zu erläutern, bei denen das Kopfzittern, wie es häufig der Fall ist, nur periodisch auftritt, bach heftigen Anstrengungen, Erregungen, stärker wird, nach Alkoholgenuss vorübergehend schwindet u. s. w., ohne dass der gleichzeitig vorhandene, permanente Nystagmus dieselben Aenderungen zeigte; kurz, es existirt zwischen beiden Zitterbewegungen kein causales Verhältniss, sondern beide Bewegungen sind als nebeneinander bestehende symptomatische Effecte derselben centralen Reizvorgänge aufzufassen.

\section{Beobachtung 3 .}

[Nystagmus abhängig von binocularer Fixation - Aufhören bei seitlicher Blickrichtung - periodisch auftretendes Kopfzittern.]

R. Josephine, 23 Jahre alt. Eltern gesund; keine nervöse Disposition in der Familie, die Geschwister sehen gut, schielen nicht.

Die Patientin selbst war stets gesund, ist kräftig gebaut, hat normale Kopfmaasse, Strabismus convergens des linken Anges seit dem 8. Lebensmonate bestehend. 
Rechts: Em. $\mathrm{S}=1$.

Links: starke Amblyopie $\mathrm{S}=$ Finger in $10^{\prime}$ (ophthalmoskopischer Befund normal. Gesichtsfeld frei. Farbenempfindung: normal.

Beiderseits stark rotirender Nystagmus (von der Umgebung der Kranken schon in deren frühester Kindheit bemerkt). Der Grad des Nystagmus variirt besonders nach sensoriellon Einflüssen, er zeigt eine auffallende Abhängigkeit von der binocularen Fixation.

Wird eins der fixirenden Augen mit der Hand bedeckt, so hört der Nystagmus des anderen (auch des sehschwachen) $\Delta$ uges sofort entweder vollständig auf oder verliert doch ganz bedeutend an Intensität. Bei seitlicher Blickrichtung hört der Nystag mus beiderseits vollständig auf, sobald das Blickfold des einen Auges von der Fixation ausgeschlossen wird. Man kann die Grenze durch Visiren über das Fixationsobject und den Nasenrücken genau controliren.

Der Nystagmus zeigt dieselbe Abhängigkeit von der seitfichen Blickrichtung bein Sehen in die Ferne sowohl, als beim Sehen in die Nähe!

Wenn die Patientin längere Zeit, 30 Minuten und darüber, in gebücter stellung arbeitet, treten zitternde Bewegungen des Kopfes auf, bei welcher derselbe unwillkürlich in seitlicher Bahn zu wackeln beginnt. Das Gefuhl des Kopfzitterns wird für die Patientin nach und nach so lästig, dass sie oft genöthigt ist, die Arbeit (Stricken, Nähen etc.) zu unterbrechen. Bei fortgesetzter Arbeit tritt auch Zittern der Hände auf, welche das Strick- oder Nähzeug balten, so dass längere Ruhepausen für die Kranke ein nothwendiges Bedürfniss werden.

Es wurde bei der Patientin im Verlaufe von 4 Wochen zuerst eine Tenotamio des Internus rechts, dann des Internus links, und als beide nicht genügend waren, schliesslich eine Vornähung des Externus rechts gemacht. Rücksichtlich der Schielstellung hatten die Operationen den gew ünschten Erfolg; der Strabismus wurde beseitigt. Der rotirende Nystagmus bestand ganz unverändert fort. 
Beobachtung 4.

[Zuckender Nystagmus, ahhängig von der Convergenz; periodisches Kopfwackeln; epileptoide Anfälle.]

Sp., Adolph, 9 Jahre alt, stammt aus gesunder Familie. Der Vater ist in hohem Grade kurzsichtig.

Der Patient hat seit frühester Kindheit an Nystagmus gelitten, die Eltern haben denselben schon am Kinde in der Wiege bemerkt. Damals hatte der Patient häufige epileptiforme Anfälle, die sich später immer seltener wiederholten, aber auch jetzt noch bisweilen vorkommen.

Die Intensität der Nystagmusbewegungen soll mit den Jahren nachgelassen haben,

Schon seit frühester Jugend besteht periodisches Kopfzittern. Wenn der Pationt ruhig ist, vergehen längere Pausen, innerhalb welcher das Kopfzittern nicht $\mathrm{zn}$ bemerken, dann erfolgen die Kopfbewegungen wieder kürzere oder längere Zeit; sie treten regelmässig hervor, wenn der Patient aufgeregt oder ängstlich wird, beim Spielen sich körperlich angestrengt hat u. s. w.

Es besteht beiderseits eine Hyp. von ungefähr 7 Dioptrien. Nach der Correction ist die Sehschärfe $=\frac{1}{5}$ der Normalen. Die Augenmedien sind klar, der Hintergrund, soweit zu sehen, normal. Die Angenbewegungen normalweit möglich, kein Strabismus, keine Insufficienz.

Der Nystagmus hat die Form rhythmischer Zuckungen. Nach 2 bis 3 starken Zuckungen erfolgen mehrere schnelle Oscillationen von geringer Schwingungsamplitüde.

Es erfolgen durchschnittlich 150 Zuckungen in der Minute. Dieselben sind am stärksten bei forcirten Seitenwendungen. Bei hochgradiger Convergenz auf $7 \mathrm{Cm}$. und näher lässt die Intensität des Nystagmus bedeutend nach. Bedecken eines Auges hat auf die letztere keinen merklichen Einfluss.

Das neben dem Nystagmus vorkommende Kopfzittern hat bisweilen den Charakter rein automatischer Bewegungen, die von bestimmten centralen Reizvorgängen nothwendig abhängen müssen und das Zusammengehören des Kopf- und Augenzitterns als neuropathische Er. scheinung und die symptomatologische Natur beider Arten 
von Bewegungsstörung fast ausser Zweifel setzen. (Vergl. Fall 5 und 13.)

Das ungemein empfindlich ausgebildete Reflexverhältniss, welches zwischen Augen- und Kopfdrehungen existirt, und in neuester Zeit besonders von Donders studirt worden ist, weist schon auf einen innigen Connex beider Bewegungen hin. Die funktionelle Abhängigkeit beider Bewegungen von denselben Centraltheilen wird aber besonders wahrscheinlich gemacht durch die klinische Erfahrung und durch zahlreiche Experimente.

Vorzugsweise gehören hierher die 59 von Prévost*) beschriebenen Krankheitsfälle, in welchen bei bestimmten Laesionen des Gehirns entsprechende Augen- und Kopfdrehungen vorhanden waren, sowie die von demselben Autor angestellten Experimente.

Von Wichtigkeit ist der Umstand, dass in ungewöhnlich vielen Fällen neben den charakteristischen Kopfund Augendrehungen auch Nystagmus gefunden wurde. (Vergl. p. 264.)

Auch unsere Fälle 1, 3, 4, 5, 11, 13, 15, 26 sind geeignet, das Abhängigkeitsverhältniss der Kopf- und Augenbewegungen $z u$ illustriren.

Beobachtung 5.

[Zwangsbewegungen des Kopfes und Kopfzittern. Rhythmische Zuckungen der Lider - Nystagmus. - Bei einem Idioten.]

Gr., J., 30 Jahre alt, aus Ruprechtsau bei Strassburg (Pfründner des hiesigen Hospitals) - Zwergwuchs - verkrüppelte kurze Beine - genu valgum - drücht mit der rechten Hand weniger kräftig als mit der linken. Schädel sehr klein. Spitzkopf. Flaches Hinterhaupt. Hat nicht lesen gelornt - spricht einzelne Worte, versteht leichte Sätze starker Nachahmungstriob, leichter Tremor der Hände, der Zunge.

*) J. L. Prévost: De la Déviation conjuguée des yeux et de la rotation de la tête; dans certains cas d'hémiplégie. Paris, 1868. 
Der Patient macht fortwährend Kopfdrehungen, so dass das Kinn wechselweise den Schultern genähert wird. Im Schlafe hören diese Bewegungen auf. Auch können dieselben, z. B. wenn Patient sich beobachtet sieht, willkürlich unterdrücktwerden.

Während dieser permanenten Kopfdrehungen und auch bei willkürlicher Unterdrückung derselben besteht leiehtes Zittern des Kopfes. Ausserdem sind leichte zuckende Bewegungen beider Augenlider in bestimmtem rhythmischem Tempo vorhanden.

Strabismus convergens des rechten Anges - die Sehschärfe ist nicht zu eruiren, jedoch scheinen Gläser nicht zu verbessern. Das rechte Auge scheint hocbgradig sehschwach - Pupillen reagiren beiderseits gut! Ophthalmoscopischer Befund normal. Die Beweglichkeit beider Angen, einzeln geprüft, normal. Associirte Seitenwendung nach links ausgiebig. Nach rechts folgen die Augen einem Fixationsobject nur bis zu den Blickfeldgrenzen des linken Auges. Bei weiterer Bewegung des Objectes nach rechts wird regelmässig der Kopf "gedreht. Permanenter Nystagmus. Bei Fixation eines Gegenstandes in der Medianebene und der horizontalen sowie auch beim Blick geradeaus in die Ferne schwache horizontale Oscillationen, welche bei Seitenwendung nach links fast 0 werden, bei Wendung nach rechts sich bedeutend verstärken und mit verticalen Oscillationen abwechseln.

Bei Senkung des fixirten Gegenstandes unter die horizontale, stark zuckende Bewegung der Augen nach unten langsames Zurückgehen nach oben. Nach jeder Zuckung einzeine horizontale Oscillationen.

Beim Blick nach oben stark ausgesprochene verticale Zuckungen ohne horizontale Schwingungen.

3. Ueber das neben dem Nystagmus vorkommende Lidzucken.

In einer ungewöhnlich grossen Anzahl der Fälle finden sich die Nystagmusbewegungen neben gleichzeitigen zuckenden Bewegungen der Lider vor. Es ist auffallend, dass diese häufige Complication des Nystagmus in der 
Literatur gar nicht erwähnt wird. Ich finde nur einmal des "blepharospasmus" ,zuckenden Bewegungen der. Lider" Erwähnung gethan bei No ël*). N. beschreibt zuckende Bewegungen des Orbicularis, die neben Nystag. mus bestehen und bei geschlossenen Lidern fortdauern. Bei demselben Patienten, einem Bergmanne, waren anch zuckende Bewegungen der oberen Extremitäten vorhanden.

Ausserdem findet sich bei A roolen ${ }^{* *}$ ) die Bemerkung, dass viele Albinos neben Nystagmus an Lidkrämpfen leiden.

Nichtsdestoweniger ist das Zucken der Lider, d. h. sind klonische Krämpfe des Orbicularis, eine recht häufige Begleiterscheinung; sie kommen sowohl neben dem Kopfwackeln (Fall 5), als auch ohne solches vor. Bei oberflächlicher Beobachtung scheint es, als wenn das Zucken der Lider im selben Tempo, wie die Bewegungen des Nystagmus vor sich gehen, und in einzelnen Fällen ist die Uebereinstimmung ebenso, wie beim Kopfzittern, recht auffallend. In der Regel aber ist die Intensität des Lidzuckens zu verschiedenen Zeiten sehr verschieden, verschwindet unter Umständen ganz und zeigt insbesondere eine augenfällige Abhängigkeit von der äusseren Beleuchtung derartig, dass bei greller Tagesbeleuchtung oder im Sonnenlichte die Augen unter fortdauernden Zuckungen geschlossen gebalten werden, während die Zuckungen bei diffuser schwacher Beleuchtung an Intensität nachlassen und bei künstlichem Licht oft ganz aufhören. Die Augen werden zuweilen sofort frei geöffnet, sobald die Kranken in einen mit Lampen oder Gaslicht erbellten Raum geführt werden. (Vergl. Fall 16 u. 17.)

*) Noël (Annales d'oculistiques, T, LXXII, p. 211).

**) Arcoleo (studi sull albinismo. Gazetta clin dello spédale eivico di Palexmo II, p. 15), ref. in Nagels Jahresbericht, II, p. 167). 
Immer habe ich, wie weiter unten näher erläutert werden wird, den nebenhergehenden Nystagmus in ähnlicher Weise unter dem Einflusse derselben Beleuchtungsintensitäten bedeutend variiren sehen.

Dass die physiologischen Augen- und Lidbewegungen coordinirte Muskelthätigkeiten voraussetzen, ist bekannt, wie aber die diesbezügliche Innervation gestaltet ist und von welchen Centralorganen die Coordination ron Lidund Augenbewegungen ausgeht, ist nicht ermittelt.

Vielleicht ist die von Hueguenin ${ }^{*}$ ) betonte Thatsache von Wichtigkeit, dass der Kern des Abducens nicht allein Fasern in den Abulucens, sondern anch solche in den neben ihm herziehenden Facialis abgibt.

Es wäre nach dieser Angabe Hueg uenins möglich, dass die den Orbicularis innervirenden Facialisfasern eigentlich als dem Abducens angehörend $\mathrm{za}$ betrachten seien und könnte man diese letzteren bei vorhandener Reizung der Centra der Aagenmuskelnerven für das Zustandekommen der Lidzuckungen verantwortlich machen.

Jedoch spricht vorläufig das Verschontbleiben des Orbicularis bei centraler Abducenslähmung gegen eine solche Annahme.

Von besonderer Wichtigkeit für den innigen Connex des Zitterns der Lider mit dem Nystagmus und die Abhängigkeit von denselben Centralorganen sind die von Duret**) kürzlich der Pariser Gesellschaft für Biologie gemachten Demonstrationen: Duret hat in einer Reihe von Fällen bei Hunden das Gelenkband zwischen Atlas und Hinterhaupt freigelegt und durch eine kleine Oeffnung desselben eine Sonde bis zum Boden des 4. Ventrikels

*) Hueguenin, G. (Allgemeine Pathologie der Krankheiten des Nervensystems, I. Theil, p. 265. Zürich, 1873.)

**) Duret, M. H.: Notes sur la Physiologie patholugique des traumatismes cérébraux (gazette medicale de Paris, Nro. 51, p. 621 u. f. 1877). 
vorgeschoben. - Die Laesion wurde durch die Section controlirt. -

Wenn die Sonde die Gegend des unteren Endes des Aquaeductus sylvii berührte, entstand ein richtiger $\mathrm{Ny}-$ stagmus, welcher regelmässig beim Zurückziehen der Sonde aufhörte, beim Vorschieben wieder eintrat.

Wurde mit der Sonde die mittlere Parthie des Ventrikelbodens im Niveau des Abducens- und FacialisKerns berührt, so traten mit derselben Regelmässigkeit Zuckungen der Augenlider ein.

\section{Beobachtung 6.}

[Permanenter Nystagmus - periodische Lidzuckungen Krämpfe der Frontalis - Abbängigkeit von der Beleuchtung.]

W., Eugenie, 30 Jahre alt, mit geringem Microphthalmus, leidet seit frühester Kindheit an Nystagmus, hatte früher beiderseits Cataract, welche vor 15 Jahren durch Discision operirt wurde - Bds.: Geschrumpfte Linsenresto im Pupillargebiet - Medien sonst klar. Hintergrund normal. Conjunctiva gesund.

Die Kranke zählt mit +12 Dioptr., bds. Finger in 8 bis 10 Fuss Entfernung. Das Gesichtsfeld ist frei - Farben werden leicht unterschieden.

Der Nystagmus in Form horizontaler Oscillationen zeigt keine Abhängigkeit von der Fixation oder von Blickrichtungen; dagegen wird die Intensität desselben bei künstlicher Beleuchtung ganz bedeutend vermindert. Wenn die Patientin ins helle Tageslieht tritt, wird der Nystagmus bedentend verstärkt - gleichzeitig erfolgen dann äusserst rasche, zuckende Bewegungen (Blinzeln) der Lider, 80 bis 100 in der Minute; im schwachen Tageslichte sowie bei künstlicher Belenchtung hören diese letzteren vollständig auf.

Bemerkenswerth ist, dass dio Patientin in den letzten Jahren zu wiederholten Malen in Perioden von ca. 10 tägiger Dauer starke Orbiculariszuckungen, zugleich mit Zuckungen im Frontalis gehabt hat, die beständig andauerten, rbythmisch erfolgten und endlich allmälig verschwanden. 
Beobachtung 7.

[Permanenter Nystagmus, abhängig von Blickrichtungen -

Lidzuckungen mit intermittirendem Charakter.]

B., Catharina, 19 Jahre alt, aus H., Körper regelmässig entwickelt, Kopf klein. Umfang $51 \mathrm{Cm}$, Längsdurchmesser $17,0 \mathrm{Cm}$., grösster Querdurchmesser $13,5 \mathrm{Cm}$, Meuto-occipital. Durchmesser $23 \mathrm{Cm}$. - Blödsinn geringen Grades, kann geläufig sprechen, stösst aber mit der Zunge oft an, hat nicht lesen gelernt - complicirte Begriffe fehlen - lacht fortwährend; gestikulirt viel - hereditäre Disposition - die Mutter starb in der Irrenanstalt, hatte bds. Sehnervenatrophie.

Rechts centrales Lencom, vordere Polarcataract. Iridectomie nach aussen unten.

Links Leucoma adhaerens, vordere Polarcataract. Iridectomie nach anssen oben.

Bds. $\mathrm{S}=$ Finger in $6-8$ Fuss. Gesichtsfeld frei. Farbenpereeption normal.

Beiderseitiger Nystagmus seit frühester Kindheit in Form horizontaler Oseillationen. Bei der Fixation in der Medianlinie sehr gering, bei hohen Convergenzgraden fast 0 . Beim Blick nach links, sowie beim Blick nach oben erheblich stärker. Beim Blick nach unten relative Ruhe. Der Nystagmus des rechten Auges ist stärker, als der des linken. Beim rubenden Blick in die Ferne tritt dieses Verbältniss aufälllig hervor.

Wenn die Patientin im hellen Tageslichte sich aufhielt, traten Zuckungen des Orbicularis beiderseits auf: man kann bisweilen 100 bis 150 in der Minute zählen; zu gewissen Zeiten sollen jedoch die Augen auch im grellsten Tageslichte frei geöffnei werden können.

Bei schwächeren Beleuchtungsgraden, im Zimmer, bei Lampenlicht etc. etc., lassen die Zuckungen bedeutend nach, sie erfolgen dann in ziemlich grossen Pansen, jedesmal 2 bis 3 Zuckungen, dann wieder Pause, jedoch so, dass in einer Minute der klonische Krampf mehrere Male auftritt.

In Zuständen von Aufregung werden sowohl die Nystagmus-, als auch die Lidbewegungen bedeutend stärker. 
4. Ueber den Nystagmus bei Centralkrankheiten.

a. Ueber das Vorkommen des Nystagmus bei eigentlichen psychischen Krankheiten liegen noch wenig Anhaltspunkte vor.

Der Nystagmus findet sich, wie oben pag. 245 des Näheren erwähnt, in Irrenanstalten recht häufig, meistens bei verschiedenen Graden des Blödsinns, neben Missbildungen des Körpers, des Kopfes etc. etc., doch auch ohne die letzteren und $z$ war als vorïbergehende Störung bei rein psychischen Alterationen.

Beobachtung 8 .

[Nystagmus abhängig von psychischen Aufregungszuständen bei einem geisteskranken Taubstummen.]

(Mitgetheilt von dem Anstaltsarzt Hrn. Dr. Gerge us in Stephansfeld.)

H. V., 45jähriger Pationt in der Irrenanstalt Stephansfeld ist taubstumm, leidet, wie aus seinen Gesticulationen in der Taubstummensprache hervorgeht, an häufigen Gesichtstäuschungen, geräth häufig in Aufregungszustände, muss isolirt werden etc. etc.

Während seiner Ruheperiode besteht leichter oscillirender beiderseitiger Nystagmus, der zu verschiedenen Zeiten bald in horizontaler, bald in verticaler Richtung vor sich gehen, bisweilen auch gänzlich fehlen soll. Während der erwähnten Aufregungsustände bemerkt man den Nystagmus in aufallend hohem Grade.

Links besteht leucoma adhaereus. Ueber Sehschärfe sowie über Abhāngigkeitsverhältnisse des Nystagmus von Blickrichtnngen kounte wegen des psychischen Zustandes des Patienten nichts ermittelt werden.

\section{Beobachtung 9 .}

[Zuckender beiderseitiger Nystagmus rotatorius, vor 6 Jabren gleichzeitig mit Symptomen beginnender geistiger und körperlicher Schwäche entstanden.]

H. Peter, 35 Jahre alt, hat den letaten Krieg und viele Strapazen durchgemacht, wurde verwundet und blieb seitdem 
schwächlich. Nach heftiger Erkältung im Jahre 1873 mehrere apoplectiforme Anfälle - seitdem allmählich zunehmende geistige und körperliche Schwäche - starke anarthrische Sprachstörung. Beine sind steif und sehwach - Patient fällt leicht - Gehen ist nur langsam mit Krücken möglich. Es besteht jedoch keine vollständjge Lähmung. Auch sind die Yuskeln der Extremitäten nicht atrophirt. - Keine ausgesprochene psychische Störung, sondern nur zunehmende Schwäche. Nystagmus ror 4 Jahren entstanden; anfangs nur leichtes Zittern der Bulbi, welches sich immer mehr verstärkte; gegenwärtig starke rotatorische Zuckungen beiderseits im Sinne des Uhrzeigers und dann langsamer zurück. Die Sehschärfe ist beiderseits fast intact. - Beiderseits wird Jäg. Nr. 1 in 10" fliessend gelesen. Verdecken eines Auges, verschiedene Convergenzgrade haben keinen Einfluss auf den Nystagmus. Dagegen nimmt dessen Intensitat beim Blick nach links und auch bei forcirtem Blick nach oben erheblich ab.

Der Nystagmus bei anatomischen, durch die Sektion nachweisbaren Hirnkrankheiten findet sich zuerst erwähnt bei Bright und Mackenzie.*)

Er- ist mehrmals gesehen worden bei subduralen Blutergüssen (Lépine)**) und nach Sinusthrombose (Nothnagel)***); fast regelmässig sah Fürstner $\dagger$ ) einseitigen Nystagmus, ,wenn auch in einzelnen Fällen nur vorübergehend, bei pachymeningitischen und anderweitigen Oberflächenblutungen."

Nach der kurzen Beschreibung, welche Fürstner p. 22 über diesen einseitigen Nystagmus liefert, scheint es sich mehr

*) Fano (traité des maladies des yeux, T. II, p. 661).

**) Lépine (Note sur deux cas d'hémorhagie sousmeningée gazette de Paris 1867).

***) N othnage l (Ziemssens Handbuch der Nervenkrankheiten, Bd. XII, Abth. I, p. 181).

†) Fürstner, Dr. C. (Zur Genese und Symptomatologie der Pachymeningitis haemorrhagica. Arch. für Psychiatrie, Bd. VUI, p.22). 
um atypische einseitige Augenbewegungen*) 'zu handeln, als nm jene rythmisch zitternden Bewegungen, welehe den Nystagmus charakterisiren.

Bei vorübergehender Lähmung mehrerer Augenmuskeln in Folge von cerebralen Affectionen sah $\mathrm{Be}$ nedict**) einmal passageren Nystagmus.

$$
\text { Beobachtung } 10 \text { ***) }
$$

[Bds.: Vollständige Lähmung sämmtlicher Augenmuskeln, ausgenommen den Trochlearis, der beiderseits hochgradig paretiseh ist, - Nystagmus rotatorius].

B., Carl, 21 Jahre alt, stud. philos. hat seit seinem 3. Lebensjahre nach einer Gehirnkrankheit, deren Symptome nicht angegeben werden können, eine Lähmung sämmtlicher Augenmuskeln. Die bulbi sind in Ieicht divergirender und leicht gesenkter Stellung in der Orbita fixirt, nur bei der Willensintention nach unten za sehen, treten leichte Drehungen der Augäpfel ein, welche einen Rest erhaltener Funktion im Trochlearis vermuthen lassen. Anfangs war beiderseits vollständige Ptosis vorhanden. Später ist durch Operation (Excision eines Hautstückes) das obere Lid bds. soweit gehoben, dass der Patient durch eine schmale Lidspalte sehen kann. Die ophthalmoscopisehe Untersuchung ergiebt beiderseits eine mässig tiefe totale Excavation der Papille - der intraoculare Druck ist gegenwärtig nicht erhöht.

Es besteht fortdauernder Nystagmus rotatorius, Rollungen in oscillirendem Tempo.

Der Nystagmus wird bei Gemüthsbewegungen verstärkt. Rechts ist M. $\frac{1}{11}$, links M. $\frac{1}{10}$ vorhanden, mit den Correctionsgläsern besteht bds. eine Sehschärfe von $\frac{2}{7}$ der Normalen. Ohne Gläser wird J. 1 in $5^{\prime \prime}$ nicht weiter gelesen.

*) Vergl. Raèhlmann und Witkowski (Ueber atypische Augenbewegungen, Archiv für Physiologie, Jahrg. 1877). p. 420 ).

**) Benedict (Nervenpathologie und Electrotherapie Bd. II,

***) Ein ganz ähnlicher Fall findet sich bei Schroeder. (Erster Bericht über die Augenklinik Nerothal, p. 26.) 
Die Pupillen sind different; die rechte weiter als die linke. Die Reaction auf Licht ist rollstandig erhalten. Die Accommodation ist gut. (Patient arbeitet mit seiner Brille.) Des Gesichtsfeld ist beiderseits frei - Licht- und Farbensinn sind normal.

Patient sieht nicht doppelt. Es kann aber durch Prismen Diplopie erzengt werden. Herr B. hat trotz seinen unbeweglichen Augen seine Gymnasialstudien machen können, er arbeitet gegenwärtig ganze Tage in den Archiven, übersetz alte Handschriften u. s. w. Alle Angenbewegungen werden durch Kopfbewegungen ersetzt. Beim Lesen, Schreiben ete. etc. wendet der Patient den Kopf zur Seite, so dass das andere Gesichtsfeld eliminirt wird.

\section{Beobaehtung 11.*)}

[Nystagmus seit 1/1/2 Jahron, gleichzeitig mit Störungen des Gleichgewichtes entstanden - Sektion: Cysticercusblasen im Gehirn.]

F., J ulie, geboren 1840, gestorben 1878. Wegen Idiotismus seit 1857 in der Irrenanstalt Stephansfeld. Das linke Auge seit frühester Kindheit cataractös. Bis $1 \frac{1}{2} \mathrm{Jahr}$ vor dem Tode war kein Nystagmus vorhanden. Derselbe trat in merkbarem Grade erst auf, als sich der Zustand der Kranken auch in anderer Beziehung änderte. Es stellten sich Motilitätsstörungen ein - Patientin konnte sich weniger sicher bewegen, fiel oft um. In den letzten Monaten vor dem Tode war das Gehen auch mit Unterstützung durchaus unmöglich - die Patientin fiel, auf die Füsse gestellt, regelmässig nach links und hinten um.

Tod am 14. April 1878.

Sektion: Schädeldach - Längsdurehmesser $17,5 \mathrm{~cm}$, Breitendurchmesser $15 \mathrm{Cm}$. - assymetrisch verdickt; schwer, fast ganz ohne Diploë. Näthe aussen sämmtlich leicht zu erkennen. Crista galli kolbenförmig verdickt. Keine Adhaerenzen der Dura und der inneren Schädelfläche - Dura anämisch. Entsprechend dem linken Parietallappen an der Innenseite der Dura eine starke Membran. Linker Opticus scheint dicker, als der rechte und ist derselbe von einem leicht zerreisslichen,

*) Ich verdanke die Beobachtung sowie den Sektionsbefund der Güte des Herrn Direktors $\mathbf{S}$ tark in Stephanșfeld. 
weissgelben Belage, der einige Gefässe enthält, umgeben. Hirnanhang vergrössert und im Wesentlichen in eine eingedichte, eiterähnliche, gelbe Masse verwandelt.

Pia auffallend anämisch, besonders rechts, mit Ausnahme des dem Occipitallappen entsprechenden Theiles ist sie weisslich getrübt.

Am linken unteren Scheitellappen überdeckt die Pia in einem Sulcus eine schmale Blase von $4 \mathrm{Cm}$. Länge, welch $\theta$ die Gyri etwas auseinandergedrängt hat. Desgleichen finden sich Blasen von verschiedener Grösse an folgenden Stellen:

1) Oberhalb des linken Nervus optieus auf demselben liegend, 2) unterhalb des Chiasma links hinten, 3) auf der Seite des rechten tractus opticus gegen die sylvisehe Grube, 4) unterhalb der mittleren und vorderen Ponsregion, 5) über dem linken Crus cerebelli ad pontem und der anstossenden Kleinhirnparthie. Die Membran der Blasen besteht aus einem zarten, weisslichen Häntchen, der Inhalt ist (macroskopisch) eine wasserklare Flüssigkeit. Nach Entfernung der Blasen fliesst aus den Seitenventrikeln eine grosse Menge Flüssigkeit $a b$.

Die Hirngefässe sind von einer dicken, weisslichen, gewulsteten Membran überdeckt. $\nabla$ on den Hirnnerven sind in diese Membran eingebettet: 1) Die hintere Region der Nerv. olfactorii. 2) Beide nervi opt. mit Chiasma und tractus. 3) Beide oculomotorii, besonders der linke. 4) Der linke Abducens.

Gefässlumen der Carotis interna scheint beiderseits durch die starre Membran ziemlich verengt. Nach dem Abziehen derselben vom Hirnstamme tritt der Boden des 3. Ventrikels als eine theilweise, vollständig durchsichtige und dem Zerreissen nahe dünne Lamelle hervor. Mit der Pia lässt sich die Membran überall ohne Verletzung der Hirnsubstanz abziehen.

Isolirung von Membran, Pia und Gefässen ist unmöglich. Die Gefässe selbst anscheinend unverändert.

Starke Dilatation beider Seitenventrikel und deren Hinterhörner, Ependym von reichlichen, auffallend starken Granulationen besetzt, besonders die Region des Streifen und Sehhügels, reichlich damit bedeckt. Streifen und Sehhügel beiderseits stark abgeplattet. Septum in eine dunne derbe Membran verwandelt.

Die Kleinheit der Grosshirnganglien sehr auffallend. Bei Schnitten durch dieselben von einer be- 
dentenden Menge erweiterter Gefässe durchsetzt. Blutvertheilung in denselben sehr ungleichmässig, besonders in den weissen Schichten, welche zum Theil ganz roth gefärbt erscheinen.

Von den Ventrikeldecken hat der Balken noch eine auffallende Mächtigkeit.

Im hinteren Winkel der linken Fossa sylvii findet sich ein gelber Erweichungsherd.

Die Erweichung ist in der Rinde der zwischenliegenden Lulci stärker ausgesprochen, als auf der Höbe der Gyri. An der oberen Kante der hinteren Parthie der ersten Frontalwindung links und des oberen Scheitellappens finden sich rerschiedene gelbe Erweichungsherde von unregelmässiger Form; desgleichen an der Spitze der zweiten linken Frontalwindung. Im rechten oberen Scheitellappen findet sich ein käsiger Knoten.

Grane Hirnsubstanz anämisch, Rinde sehr sehmächtig; die einzelnen Gyri überall bedentend abgeplattet.

Kleinhirnsubstanz blass, oedematös; Boden des 3. Ventrikels dicht mit Granulationen besetzt. Pons and Modulla sehr blass, makroskopisch normal.

Brusthöhle: Bindegewebige Adhaerenzen zwischen Lunge und Pleura. Oedem des rechten Unterlappens, Verdickung und Schrumpfung der Mitralis.

Bauchhöhle: Divertikel im S romanum.

Bei Hemiplegien in Folge von Hirnapoplexien ist relativ häufig Nystagmus beobachtet worden und meistens gleichzeitig neben einer charakteristischen Drehung der Augen zur Seite. Ausser der Drehung der Augen war meist eine ebensolche des Kopfes vorhanden. Nach Prévo st*), der unter dem Namen der deviation conjugué des yeux dieses auffallende Symptom zuerst beschrieben hat, findet sich bei Apoplexien in der Grosshirnhemisphäre die Ablenkung der Augen sowie des Kopfes nach der Seite der afficirten Hemisphäre hin. Bei Affection der tieferen Theile des Gehirns dagegen, insbesondere der

*) Préyost, I. c. 
Pons, medulla, des Kleinhirns etc. etc. findet die $\mathrm{Ab}$ lenkung nach der entgegengesetzten Seite hin statt. Die Fälle von Prévost, bei welchen Nystagmus beobachtet wurde, sind meist aus der Abtheilung von Charcot, von dem auch die Protokolle stammen, mit Ausnahme des Falles 31, der von Vulpiaus Abtheilung stammt.

In allen mit Nystagmus complicirten Fällen fanden sich bei der Autopsie Veränderungen, meist apoplectische Herde in den tieferen Gehirnparthien und zwar bei den Fallen 25, 26, 31 and 44 im Streifenhitgel und in den Fällen 49 und 51 im Sehhügel.

In allen von Prévost mitgetheilten Fällen fanden sich niemals die vorderen, sondern stets nur die hinteren und tieferen Hirntheile lädirt.

In sämmtlichen 12 Fällen, bei welchen $\mathrm{Ny}$ stagmus vorkam, war neben der Augendrehung die entsprechende Kopfdrehung vorhanden und mit dem Verschwinden der letzteren verschwand auch der Nystagmus.

Es scheint also nach diesem Verhalten, dass der Nystagmus bei Hirnkrankheiten eine ganz enge Beziehung zu bestimmten Kopfdrehungen hat, eine Beziehung, welche wir, wie schon oben erwähnt (pag. 249), auch bei gewöhnlichen Formen des Nystagmus ausgesprochen finden, auch wenn eine Abhängigkeit von Hirnkrankheiten sich nicht nachweisen lässt.

Gadaud*) berichtet über einen Fall von Hirnverletzung durch Fall auf den Kopf; es zeigte sich während des Lebens vorübergehend hettiger Nystagmus.

Bei der Obduction fand sich eine Zerreissung des rechten Corpus restiforme, die Risswunde dehnte sich nach vorn bis zum Boden des vierten Ventrikels aus.

In neuester Zeit ist vorübergehender Nystagmus bei

*) Gadaud (1. c., p. 34). 
Ohrenleiden beobachtet worden. Schwabach*) hat durch Druck auf das angeschwollene Ohr Nystagmus erzeugt und E. Pflüger**) sah ebenfalls bei mehrmaligen Versuchen behufs Entfernung eines Polypen aus dem Ohre regelmässig vorübergehend Nystagmus auftreten. Cyon ${ }^{* * *}$ ) hat bekanntlich durch Reizung des Acusticus Augenbewegungen reflectorisch hervorgerufen and ist es höchst wahrscheinlich, dass auch bei den von S. und Pf. beschriebenen Nystagmusfällen eine Fortleitung der Reizung vom Acusticus aus auf die Kerne der Augenmuskelnerven stattfand. Da die Wurzeln des Acusticus jedenfalls in der Gegend der striae acusticae in der Rautengrube ihren Ursprung nehmen, so spricht dieses Reflexverhältniss deutlich für eine Abhängigkeit des Nystagmus von den genannten Centralorganen.

b) Auch experimentell ist vielfach nach Verletzung der genannten tieferen Hirntheile Nystagmus hervorgebracht worden.

In einem Anhange der erwähnten Arbeit von Prévost pag. 104 finden sich 11 Experimente angeführt.

Mit einem 2-3 Mm. breiten Bohrer wurde das rechte Schädeldach perforirt und das Instrument dann tief eingestossen. In 3 Fällen trat neben der Ablenkung der Augen und des Kopfes Nystagmus ein. Bei der Nekropsie zeigte sich in allen 3 Fällen vorzugsweise der Streifenhügel, dann aber auch der Sehhügel verletzt; im Falle 9 fand sich der Streifenhügel fast ganz "weggenommen, der Sehhügel war von Blut durchtränkt.

Von grösstem Interesse sind die Arbeiten Vul-

*) Schwabach: Deutsche Zeitschrift für praktische Medicin Nr, 11, J. 1878.

**) P flüger, Prof. E., ebenda, Nr. 35.

***) Cyon: Gazette médicale de Páris, 1876. 
piau's*) rücksichtlich der Functionen des vierten Ventrikels.

Er notirt bei 13 Experimenten 6 Mal Nystagmus also fast in der Hälfte aller Fälle und in diesen 6 Fällen war der Boden des vierten Ventrikels jedesmal verletzt.

In den übrigen Fällen dagegen, bei denen sich kein Nystagmus zeigte, war bei der Verletzung regelmässig der vierte Ventrikel verschont geblieben.

Die Vulpiau'schen Experimente sind oft wiederbolt; in neuester Zeit hat Duret der Pariser Academie bestätigende Experimente demonstrirt, welche oben pag. 256 bereits kurz referirt wurden und für uns um so interessanter sind, weil auch Lidzuckungen ausser dem $\mathrm{Ny}$ stagmus bei Verletzung des Ventrikelbodens beobachtet wurden.

Auch bei Verletzungen des Kleinhirns ist Nystagmus beobachtet worden.

Onimus leitet das Zittern überhaupt vom Kleinhirn her; nach ihm wird rhythmisches Zittern des Kopfes (Kopfwackeln) bei Enten hervorgebracht, wenn man einen Theil des Kleinhirns zerstört.

Nach Hitzig**) treten nach Durchschneidung des Flockenstiels Augenbewegungen auf und nach Extirpation der Flocke Nystagmus.

Nach Curschmann ${ }^{* * *}$ ) tritt constant Nystagmus auf nach vorsichtiger Verletzung des mittleren Kleinhirnschenkels.

*) Vulpiau (Recherches expérimentales relatives aux effets des l'ésions du 4 ventricule etc. etc. mémoires de la société de biographie 1861).

**) Hitzig, E. Weitere Untersuchungen zur Physiologie des Gehirns. Archiv für Anatomie und Physiologie 1871, pag. 771).

***) Curschmann (Berliner med,-psychologische Gesellschaft, Berl. klin. Wochenschrift, pag. 33). 
Nach Hitzig*) bringt ein durch den Hinterkopf geleiteter constanter Strom zuckenden Nystagmus hervor. H. führt denselben auf Reizung des Kleinhirns zurück. Bei Application stärkerer Ströme treten auch Dreh- und Rollbewegungen auf.

Schliesslich wäre hier auf die Versuche von $\operatorname{Exner} * *$ ) zu verweisen, welcher bei der experimentell erzeugten Manière'schen Krankheit der Kaninehen starken Nystagmus auftreten sah, sobald die Thiere im Rollen aufgehalten wurden.

Wenn wir nun die oben citirten Befunde bei den erwähnten Hirnlaesionen mit den Resultaten des Experimentes an Thieren vergleichen, so kommen wir zu dem Schlusse, dass vorzugsweise bei Affectionen des Streifenhügels, des vierten Ventrikels, der Corpora restiformia und des Kleinhirns Nystagmus beobachtet wird und zwar in einem solchen Häufigkeitsverhältnisse, dass man nothwendig auf eine funktionelle Abhängigkeit des Nystagmus von den genannten Theilen zurückschliessen muss.

Mōgen auch die Fălle von Prévost die differenzialdiagnostische Bedeutung rücksichtlich des Sitzes der Gehirnaffection nicht haben, welche man ihnen anfangs zuschrieb (Bernhard)***), so sind doch, was den Nystagmus angeht, unsere Kenntnisse bisher noch so dürttig, dass es mindestens

*) Hitzig (Ueber die beim Galvanisiren des Kopfes entstehenden Störungen der Muskelinnervation und der Vorstellung vom Verhalten im Raume, 1. c., p. 716).

**) Exner, Sigmund (Menière'sche Krankheit bei Kaninchen. Sitzungsberichte der Wiener Akad. Math.-Naturwissen. Klasse 70, Abth.III, p. 153).

***) Bern hardt (Ueber den diagnostischen Werth der Symptome der Déviation conjuguée bei Hirnkrankheiten, Virchow's Archiv, Bd. 69. 1.) 
voreilig wäre, die Wiehtigkeit der Prévost'schen Fälle für die klinische Bedeutung des Nystagmus bei Hirnkrankheiten zu unterschätzen.

Eine Verletzung resp. Erkrankung der vorderen und auch der oberflächlichen Parthien des Gehirns, überhaupt der Centraltheile, welche von dem centralen Verlaufs. gebiete der Augenmuskelnerven und deren Kernen entfernter liegen, scheint für das Zustandekommen des Nystagmus von auffallend geringer Bedeutung zu sein.

Am meisten noch scheinen Oberflächenblutungen zu disponiren (Lépine, Fü rstner).

Mit dem Gesagten stimmt vollständig überein, dass, wie ich von Herrn Dr. Gergens durch mündliche Mittheilung erfahren, bei den interessanten Goltz'schen Gehirnversuchen, bei denen grössere Theile der Oberfläche vollständig entfernt werden, niemals Nystagmus beobachtet wurde. - In einem Falle, in welchem Nystagmus auftrat, fanden sich auch die tieferen Gehirntheile, insbesondere die Vierhügel verletzt.

Endlich weist bei Vergleichung vorstehender Resultate das in der Mehrzabl der Fälle beobachtete Zusammenvorkommen von Kopfdrehungen und Nystagmus auf dieselbe funktionelle Abhängigkeit des Kopf- und Augenzitterns von jenen genannten Centralorganen hin, eine Abhängigkeit, welche schon bei Besprechung des Kopfzitterns pag. 251 als wahrscheinlich erwähnt worden ist.

c) Ueber den Nystagmus bei disseminirter Sclerose.

Bei dem durch Charcot und Vulpiau*) definirten Symptomencomplexe der disseminirten Sclerose kommt

*) Charcot und Vulpian in mehreren Arbeiten seit 1865. Vergl. die Literatur der diss. Sclerose bei Eirb. (Die Krankheiten des Rückenmarks. Ziemssens Handbach Bd. II, p. 87, Leipzig 1877.) 
sehr oft Nystagmus vor. Nach Charcot findet er sich in der Hälfte der Fälle.

Auch dessen Schüler kommen in ihren Zusammenstellungen zu demselben Resultate. (Magnan*), Jof$\operatorname{froy}^{* *}$, Lionville***) a. a.) In manchen ausgeprägten Fällen fehlt der Nystagmus. (Leube $\dagger$ ), Hirseh $\dagger$ ) u. a.)

Wie das „Intentionszittern" der übrigen Körpertheile, so zeigt auch der Nystagmus besondere Abhängigkeit von den Willkürbewegungen, so dass derselbe vorzugsweise deutlich auftritt, wenn bei bestimmten Fixationsbestrebungen Augenbewegungen eingeleitet werden.

Immer ist neben dem Nystagmus auch Zittern des Kopfes vorhanden.

Der Nystagmus bei disseminirter Sclerose findet sich in der Literatur zwar öfter erwähnt, aber nur sehr selten genau beschrieben.

In einem Falle von Gadaud $\dagger$ i) dauerte der Nystagmus permanent an und zwar in Form von Zuckungen. Beim Blick nach links nahm derselbe bedeutend ab; steigerte sich aber enorm, wenn ein Gegenstand fixirt werden sollte, und es traten beim Bestreben zu fixiren gleichzeitig Schüttelbewegungen in anderen Muskelgruppen auf. Eine Angabe über Sehschärfe etc. etc. fehlt in der Beschreibung.

Bei Ordenstein ${ }^{*}+$ ) findet sich Nystagmus notirt in einem Falle, in welchem bei der Section die sclerotischen Herde, besonders im verlängerten Mark, gefunden wurden.

*) Magnan (Gazette médicale de Paris, Nr. 14, 1870).

**) Joffroy, A. (ebenda, Nr. 22 u. 24.)

***) Lionville, H. (ebenda, Nr. 19 u. 20.)

t) Leube (Archiv für klinische Medicin, Bd. VIII.)

††) Hirsch (Ueber Sclerose des Gehirns und Rückenmarks. Deutsche Klinik Nr. 38 u. 38, 1870).

++ ) Gadaud (l. c., p. 38).

* +) Ordenstein (Sur la paralysie agitaute et la sclérose en plaques gênéralisée, Thése de Paris, 1868). 
In den von Gadaud referirten Fällen fanden sich die Herde ebenfalls in den tieferen Gehirntheilen besonders zählreich vor.

\section{Beobachtung 12.*)}

[Permanenter Nystagmus, beim Wechsel der Fixation stärker, allgemeines Intentionszittern seit 6 Jahren.]

Die klinischen Symptome finden sich genau beschrieben bei Leyden (Rückenmarkskrankheiten). Ich entnehme aus p. 392: „Multiple clerose mit Ataxie. Allmäliger Beginn in Folge ron Erkältungen und Anstrengungen - Besserung schubweise Verschlimmerung. Schmerzen im Kopf, Rücken, Armen und Beinen, nicht sehr heftig. Stossweise, zuckende, zum Theil schleudernde Bewegungen, besonders im linken Arm. Schwäche der Beine, so dass schliesslich das Gehen und Stehen unmöglich ist; fehlendes Gleichgewicht. Sensibilität anscheinend intact, lebhafte Reflex- und Huskelerregbarkeit. Incontinentia urinae. Sehschwä,che. Nystagmus. Sprache intact. Progressiver Verlauf."

Bei der Untersuchung der Augen am 12. März 1878 fand ich folgendes:

Medien beiderseits klar. Papille beiderseits graublau verfärbt, leicht muldenförmig excavirt, scharf begrenzt. Bindegewebsring ringsum deutlich sichtbar.

Ungewöhnlich starke Verdünnung der arteriellen Gefässe, weniger anffallende Verdünnung der Venenstämme.

Sehschärfe beiderseits stark herabgesetzt, rechts mehr als links. - Doch werden noch Finger in ca. 8-10' gezählt.

Gesichtsfeld ist beschränkt, jedoch nicht sehr erheblich.

Farbige Pigmente werden von der Patientin noch gut unterschieden.

Pupillen sind beiderseits gleich; Reaction auf Licht und auf Accoramodationsimpulse gut erhalten.

Wăhrend der Ruhelage der Augen geringgradiger, aber permanenter horizontal-oscillixender Nystagmus.

Wenn die Augen zur Seite nach rechts oder links gerichtet

*) Aus der medicinischen Klinit des Hern Geheimrath Kussmaul. 
sind, ist derselbe weniger stark, als bei der Blickrichtung geradeans oder bei Convergenzstellungen.

Wenn aber die Augen, um verschiedene Blickrichtungen vorzunehmen, aus der jeweiligen Ruhelage zu Bewegungen ubbergehen, d. h. wenn die betreffende Patientin aufgefordert wird, einen Gegenstand zu fixiren oder einem fixirten Gegenstande, der sich bewegt, zu folgen, so treten lebhafte Schwankungen der Augen (Oscillationen in besonders grossen Excursionen) auf und erst nach einer gewissen Reihe stetig kleiner werdenden Sehwingungen tritt wieder relative Ruhe ein. Es besteht Kopfzittern von verschiedener Intensität, welches bei Vornahme willkürlicher Bewegungen unabhängig vom Nystagmus sich steigert.

\section{Beobachtung 13.}

[Zwangsbewegungen des Kopfes und der Augen (Manègebewegungen), beim gewaltsamen Halten des Kopfes Nystagmus — höchstgradiger Idiotismus. - Obduction: Ungewöhnlich starke Dilatation der Ventrikel - Degeneration der Hemisphären - disseminirte Selerose, besonders des Hirnstammes*).]

H., Carl, 2 Jahre alt, wurde in die Kinderabtheilung des biesigen Hospitals aufgenommen am 24. November 1877, starb am 4. December 1877.

Hereditäre Disposition; die Mutter war verschiedene Male in der Irrenanstalt.

Ziemlich grosses, starkes, nicht abnorm entwickeltes Kind. Kopf: klein, namentlich der Hinterkopf. Unterkiefer verhältnissmässig stark entwickelt, Fontanellen fest geschlossen. Näthe stark verknöchert. Die 4 oberen Schneidezähne vollständig abgeschliffen durch die fortwährend stattfindenden Mahlbewegungen des Unterkiefers.

Patient schreit beständig, entbehrt offembar jeglicher Intelligenz. Das Kind versteht nichts, kann weder sprechen noch sich irgendwie verständlich machen, kann nicht stehen etc.

Auf heftige Geräusche, Anschreien in die Ohren, rufen, erfolgt absolut keine Reaction, wobl aber auf sensible Hautreize (Kneipen, Nadelstiche).

*) Krankengeschichte und Sectionsbefund verdanke ich der Güte des Herrn Prof. Kohts. 
Giebt man dem Kind Flüssigkeiten oder irgend welche Nahrung ein, so finden nur dann Sehluckbewegungen statt, wenn das Dargereichte den hinteren Pharynxraum berührt und reflectorisch Schluckbewegungen ausgelöst werden. Es macht den Eindruck, als ob willkürliches Schlucken nicht stattfande.

Auffallend sind unanfhörliche Bewegungen des Kopfes ron einer Seite zur andern, welche ron der Geburt an (nach Aussage der Mutter) ununterbrochen bestehen und nur während des Schlafes aufhören.

Rücken ist stark gekrümmt, Rippen an den hinteren Theilen stark convex. Beiderseits stark entwickelter pes planus. Anzeichen von Rachitis oder Scrofulose sind nicht vorhanden.

Arme liegen fest dem Rumpfe an; Oberschenkel adducirt. Man ist nur mit einiger Muthe im Stande, die Arme vom Rumpf, die Oberschenkel vom Leib zu entfernen, dieselben kebren gleich in die frühere Lage zurück.

Finger und Daumen meistens in die Vola manus eingeschlagen, sind nur mit gewisser Anstrengung gerade zu strecken und kehren, wenn die gewaltsame Streckung aufhört, sofort wieder in Flectionsstellung zurück.

Durchșchnittliche Temperatur $38^{\circ}$, fast täglich mehrmaliges Erbrechen schleimiger Massen.

Kurz vor dem Tode Aufhören der Kopfbewegungen. Augenbefund rom 1. December 1877 .

Die beiden Angen führen unaufhörlich (und angeblich schon seit der Geburt) associrte Seitenbewegungen aus, welche im selben Sinne wie die erwähnten Kopfbewegungen und im selben Tempo, 50 bis 60 in der Minute, erfolgen und so ausgiebig sind, dass bei einex Kopfdrehung nach rechts z. B. die rechte Pupille die aussere Lidcommissur erreicht. Wird der Kopf in irgend einer Lage festgehalten, so erfolgen stark zuckende Bewegungen beider Augen in rhythmischer Weise. - Während des Schlafes sind die Bewegungen der Augen ebenso wie die Kopfbewegungen nicht vorhanden. Pupillarreaction, sowie Augenhintergrund sind wegen der beständigen Bewegungen nicht zu prüfen - doch sind die Medien klar - ophthalmoskopisch rother Reflex von allen Theilen des Grundes.

Section (durch Prof. von Recklinghausen): Kopf klein; ausserordentlich starke Entwicklung des paniculus adiposus. 
Beim Abnehmen des Schädeldaches zeigt sich gleich, dass der Schädelraum rom Gehirn nicht vollständig ansgefült wird. Gehirn wird mit dom Schädel zusammen herausgenommen, es fliesst eine ziemliche Quantität Flüssigkeit (Serum), zwisehen Gehirn und Dura an der Convexität und Basis angesammelt, ab.

Feste Gerinnsel im Sin transversus, torcular, sinus sigmoideus; geschichtet; - die blassen Parthien etwas brüchig. Beide plana orbitalia springen vor, so dass zwei sehr tiefe Mittelhirngruben vorhanden sind.

Links ziemlich starke Wulstung der Felsenbeinpyramide.

Dura meist weiss, hie und da mit grauen Flecken verseben; auf der Dura eine schwer abzuhebende vascularisirte Schicht. Dura mater trennt sich auffallend sehwer vom Schãdel ab.

Schädelbasis sehr schief, linke Halfte $138 \mathrm{Mm}$. lang, die rechte eben so lang. Linke Hälfte promnirt stark nach hinten, während sie an der Stirn zurüekweicht; an den Schläfenbeinen Hervorwölbung; stärker links als rechts! Schädelgewölbe anch sehr schief. Linkes os. parietale sehr stark gewölbt.

Nähte noch deatlich vorhanden; nur fehlt die Stirnnath; an ihrer Stelle starker Wulst.

An Stelle der Grosshirnhemisphären ausserordentlich fluctuirende Massen, die meist nur aus dünnwandigen Blasen bestehen, die nur in den Seitentheilen eigenthümliche, hellgelbe Windungen zeigen.

Speciell promniren an der Basis zwei grosse, dünnwandige Blasen, correspondirend den beiden Mittellappen.

Von diesen beiden Theilen gehen zahlreiche Membranen zur Dura herüber, bestehend aus sehr durchsichtigem, vascularisirtem Gewebe. Das Grosshirn ist an der Spitze der beiden Stirnlappen adhaerent an der Dura mater. Beim Hin- und Herlegen des Gehirns entleert sich allmälig viel Flüssigkeit,

An den Stirnlappen bestehen die Blassen aus ganz durchichtigen Membranen; nur die beiden Hinterhauptlappen zeigen die gewöhnlichen Windungen. Die Windungen sind derb und gelb.

In dem grossen Längsspalt, entsprechend dem Balken, ist nur eine ganz durchsichtige Membran vorhanden. Unter dem Balken ist auch der Fornix in eine durchsiehtige Membran umgewandelt. Das Foramen Monroe sehr weit, so dass man bequem mit dem kleinen Finger durehkann. Ventrikel ausserv. Graefes's Archiv fiir Ophthalmologie, XXIV. 4. 
ordentlich stark dilatirt. Die innere Auskleidung ist gebildet durch eine dicke Membran mit Gefässen. Nach vorn zu schimmern gelbe, derbe Stellen durch. An der medialen Seitenwand des linken Hinterhorns sind ähnliche derbere, weissliche Einlagerungen. Der 4. Ventrikel ist nicht besonders dilatirt. Hier aufallige Verdiekung des Ependyms, so aber, dass die Oberfläche rauh, jedoch weisskörnig ist.

Olfactorii ausserordentlich glatt. Bulbi olfactorii transparent, machen den Eindruck von Cysten. Optici ausserordentlich derb und durchsichtig, Tractus noch weiss; die übrigen Nerven von normaler Beschaffenheit durehweg weiss, Vierhügel vorhanden! Thalamus optieus stark sclerosirt; sehr hart.

Pons zu klein, $18 \mathrm{Mm}$. breit, $16 \mathrm{Mm}$. hoch. Derselbe zeigt in den vorliegenden vorderen Theilen eine durchscheinende Beschaffenheit und auffallende Härte, so dass nur. der obere und untere Rand weisslich erscheinen, sogar nicht so weiss, wie die Nerven. Pedunculi cerebri sind durchscheinend, aber ohne auffallende Consistenzvermehrung.

Medulla obl. anffallend gestaltet. Pyramiden aus durchsichtiger, grauer Substans sind stark eingesunken. Oliven stark prominent, aber von rein weisser Farbe. In Folge der Verkümmerung der Pyramiden erscheint eine flache Rinne auf der medulla oblongota. Oberer Theil der medulla spinalis ist anscheinend von guter Beschaffenheit, ctwas derb. Leicht durchscheinend sind die Seitensträngo in den hinteren Partien. Die Hinterstränge sind auch etwas transparenter, als normal.

Rückenmark zeigt nichts abnormes. Nervenwurzeln auch nicht.

In den grossen Körperhöhlen keine Flüssigkeit. Lunge sehr gut aufgebläht. Wandung des linken Ventrikels sehr dünn; etwas Blut darin. Unterkiefer und Zähne etwas nach. hinten gebogen. Von den Oberkieferzähnen nur noch die Wurzeln vorhanden; deren Oberfläche in gleicher Höhe mit dem Zahnfleische sich befindet. In den Lungen ganz kleine Knötchen von weisslicher Farbe, welche auf den Durchschnitt Eiter entleeren. In den Lungenarterien, namentlich links und im unteren Lappen grosser ramificirter Thrombus, dessen fester Theil in dunkelrothe feste Gerinnung übergeht. 
Augenspalte klafft sehr weit, Augen liegen sehr tief, hauptsächlich wohl wegen starker Entwickelung des Fettpolsters an der Wange.

Die beschriebenen Zwangsbewegungen der Augen und des Kopfes haben gewisse Aehnlichkeit mit den erwähnten Erscheinungen ähnlicher Art, bei Apoplexien im Gehirn, der sogen. Déviation conjuguée der französischen Autoren. Das Verhalten des Nystagmus zu diesen $Z$ wangsbewegungen stimmt ferner ganz zu den Exner'schen Befunden, welche oben pag. 267 Erwähnung gefunden haben.

Da der sehr verbreitete Sitz der Erkrankung bei disseminirter Sclerose eine genaue Localisation der den Nystagmus bedingenden Centralstätte nicht zulässt, so wäre schon, wie auch Gadaud hervorhebt, von besonderer Wichtigkeit, wenn es sich bestätigen sollte, dass in allen Fällen von disseminirter Sclerose, in welchen Nystagmus beobachtet wurde, sich die Gegend der Medulla, der Pons, des 4. Ventrikels etc. immer vorzugsweise afficirt fände, Gegenden, welche wir aus Gründen der Analogie, wie wir gesehen haben, für die Augenbewegungen und den Nystagmus als besonders wichtige Centraltheile ansehen müssen.

\section{Beobachtung $14^{*}$ ).}

[Zuckender Nystagmus in borizontaler Richtung. - Neigung zur Kopfdrehung nach rechts. - Section: disseminirte Sclerose der tieferen Hirntheile, besonders der grossen Ganglien Optici atrophisch.]

Kaufmann Georg, 51 Jahre alt. Sehr bleicher, elender, leicht cyanotischer Mensch, in Rückenlage, Kopf meist nach

*) Krankengeschichte und Sectionsbefund verdanke ich der Güte des Herrn Prof. Jolly. 
rechts. Sehr schwacher, nicht beschleunigter Puls. Keine Temperaturerhöhung. Stirn meist leicht gerunzelt, auf beiden Seiten gleich, in beiden Gesichtshälften kein deutlicher Unterschied, nur zieht sich auf sensible Reize das Gesicht regelmässig nach rechts. Pupillen gleich, reagiren, beide Bulbi führen anseheinend anhaltend regelmässige zuckende Bewegungen aus, deren Hauptrichtung von links nach rechts zu gehen scheint. Hochgradige Taubheit auf beiden Ohren. Zunge gerade vorgestreckt, zeigt leichte fibrilläre Zuckungen. Sprache manchmal undeutlich: Gaumenlaute und $\mathbf{r}$ machen Mühe; lallend aber ohne Silbenstolpern. Sehlucken erschwert: Flüssigkeiten werden gewöhnlich durch Mund oder Nase regurgitirt. Intelligenz scheint intakt: gute Angaben seitens des Patienten über seine Krankheit.

Beide Arme sind meist schlaff, subjectiv und objectiv schwach, rechts in den Fingern manchmal leichte Contracturen, die aber vorübergehen, nach Angabe des Patienten ist auch der rechte Arm früher und stärker ergriffen worden. Bewegungen der Arme nicht ataktisch, aber eigenthümlich stossweis, ungeschickt.

Rechtes Bein nicht mehr ausgestreckt, die Muskeln des Oberschenkels stark contrahirt. Häufiges fibrilläres Zittern in demselben, noch mehr im linken Bein. Das linke Bein meist in Hüfte und Knie flectirt. Mehrmals am Tage oder in der Nacht schmerzhafte starke Extensionen beider Baine, wobei sie sich meist durch Contraction der Adductoren übereinanderlegen. Sensibilität und electrische Erregbarkeit normal. 27. Juni, Abends: $39^{\circ}$. In axilla starke rhonchi. 22. Juli: Hinfälligkeit hat zugenommen, starke Schluckstörung in den letzten Tagen. Mittags $12 \mathrm{Uhr}$ : beginnende Respirationsstörung, Abnabme der Herzthätigkeit. Um $3 \frac{1}{2}$ Uhr: Tod.

Anamnese von der Frau.

Eine Schwester soll krampfartige Zustände und Neigung zu profusen Schweissen gehabt haben, ein Kind an Hirnentzündung im 9. Jahre gestorben sein.

Vor 15 Jahren (vielleicht in Folge einer ein Jahr vorher erfolgten starken Abkühlung der Füsse, wonach die früher starken Schweisse derselben fortblieben) im linken Bein Gesehwulst ohne Röthe mit starken Schmerzen, beide gingen vorüber, die Schwäche blieb. 6 Wochen später dasselbe im rechten Bein. Fin Jahr später Einstellung der Arbeit. Seit 
1871 kann er nicht mehr gehen, seit 1 Jahre dauernd Contracturen, seit 1 Monat die schmerzhaften Contracturanfälle. Gehörverlust vor 4 Jahren binnen 7-8 Tagen unter heftigen Schmorzen und abelriechendem blutigem Ausfluss ans beiden Ohren, Mund und Nase. Seit $1 / 2$ Jabre Schwäche der Arme, Schluckbeschwerden, Sprachstörung, Sehschwäche. Verstand immer intact.

Section am 24. Juli: Prof. v. Recklinghausen. Noch ziemlich reichliches Unterhautfettgewebe; auch im Rückgratskanal ziemlich viel Fett. Sack der Dura mater spinalis leer, keine besonderen Verwachsungen zwischen Dura und Pia Dura innen und aussen unverändert, auch an der vorderen Seite Pia unverändert. Pia überall sehr weich, namentlich im centralen Halstheil und oberen Brusttheil, die vordere Seite zeigt eine mehr röthliche Farbe mit graulichem Grundton, herrührend von einer ausserordentlich durchsichtigen, fast gallertigen Beschaffenheit der von vorn her sichtbaren Strânge des Rückenmarks, während im Hinterstrang nur am Hals- und obersten Brusttheil sich gleichfalls transparente Stellen finden, die bald auf der linken, bald auf der rechten Seite die Hinterstränge, aber am Halstheile noch stärker die Seitenstränge berïhren.

Ein Querschnitt durch den oberen Halstheil zeigt die ganze Peripherie des Rückenmarks eingenommen ron einem völlig transparenten Gewebe. Diese Schicht, in wechselnder Dicke, variirt von 2-4 Mm., nur im Innern ist dann ein Kern rein weisser Substanz gebildet, die auf dem Schnitt ein klein wenig vorquillt. In der Consistenz der weissen und transparenten Stellen ist kaum ein wesentlicher Unterschied wahrzunehmen. Im oberen HaIstheile liegen diese grauen Massen namentlich in den mittleren Theilen der Hinterstränge, sowie in den der grauen Substanz anliegenden Partien des rechten Seitenstranges. In mittleren Halstheil auf dem ganzen Querschnitt gleichmässig transparente Substanz, worin nur einzelne Flecke von mehr weisslichem Ton wahrnehmbar sind. Im unteren Halstheil wieder eine Stelle, wo noch mehr von den Hintersträngen ubrig geblieben.

Im Brusttheil nimmt die weisse Substanz etwas zu, die hinteren Partien der Seitenstränge sind wieder weiss gefärbt. Diese Stellen nehmen dann zu, doch wird die Färbung weder in den Hinter- noeh in den Seitensträngen irgendwo eine rein 
normale, da überall noch transparente Beimengungen sich finden. Die Mlischung wird in dem nuteren Brust- und dem Lendentheile noch auffälliger und breiter. Im Lendentheil ist die meiste weisse Substanz in den Hintersträngen, die nur an der Peripherie etwas graue Färbung zeigen, während in den Seiten- und Vordersträngen nur einzelne weissliche Flecke vorhanden sind, letztere besonders unmittelbar an den vorderen Längsschnitt anstossend. Consistenz überall sehr gering. Pia nicht deutlich verändert. Graue Substanz von der Transparenz der Stränge nirgends za unterscheiden, nirgends qualitative Veränderungen daran zu constatiren. An einer Stelle im mittleren Brusttheil ist die Veränderung fast allein auf die Vorderstränge beschränkt, wovon sogar der rechte nicht ganz hineingezogen scheint. Hintere Wurzeln im Halstheil unveründert, im Brusttheil an ihrem Ursprung rom Rückenmark manche von etwas dünnen Fasern und etwas transparent. Vordere Wurzeln im Halstheil änsserst zart und dünnfaserig, besonders aber die dem Plexus cercicalis angehörigen weniger deutlich. Im Brusttheil ist die Differenz zu Gunsten der hinteren Wurzeln deutlicher, aber doch nicht sehr auffallig. In der Cauda equina nur wenige vereinzelte transparente und dünnere leicht röthliche Fasern.

Gehirngewicht 1311,0 Gramm.

Schädeldach sehr dick, Näthe etwas einfach, Dura nach vorn stark adhärent, auch mit der Pia ausgedehnte Verwachsungen, speckhäntige Gerinnsel im Sinus. Pia der Convexität stark verdickt, besonders auf dem Scheitel und nach den Stirnlappen $\mathrm{zu}$, weisse Streifen und namentlich weissliche Fleckchen sind rorhanden. Im oberen Längsspalt keine besondere Verwachsung, doch an dem Balken oberflächlich in der Mittellinie ein Zug transparenter Substanz, von etwas weebselnder Breite, bis zu $3 \mathrm{Mm}$. An der Basis die Alfactorii, besonders die Bulbi sehr transparent, optici stark atrophisch und durchscheinend, aber auf dem Querschnitt noch fein, aber deutlich punktirt, an den Trigeminis beiderseits grosse Transparenz an der Ursprungsstelle, namentlich der Radix major. Rechter Oculomotorius intact, im Verlauf des linken eine geringe Transparenz, ebenso am Abducens. Beide Ganglia Gasseri scheinen normal. Beide Acustiei in eine ganz gallertige Masse umgewandelt, Faciales dagegen normal. An den folgenden Hirnnerven nur leichte 
Differenzen zu Gunsten der linken Seite. Pia am Pons unverändert, leicht abziehbar, ebenso an der Medulla oblongata. Pons - Oberfläche sehr fleckig, und zwar sind graue eingesunkene und transparente Stellen vorhanden, vorn mehr als hinten. Dieselbe Veränderung in den oberflächlichen Schichten der Hirnstile, ein Ursprung des Pons continuirlich ausgebildet, weiter im Pons dieselben transparenten eingezogenen Stellen fleckenweise. Tractas optici continuirlich transparent, nur an der Kreuzungsstelle mit dem Pedunactus treten weisse Flecke auf. Medulla oblongata in ihren äusseren Schichten ringsum durch transparentes Gewebe gebildet, nur nach hinten zu im Corpus restiforme einzelne Schichten woissen Gewebes.

Das ganze Gehirn ungemein weich, Pia mater auch an den Sulcis leicht abtrennbar. Seitenventrikel nur mässig weit, Hinterhörner fehlen; beiderseits Ependym überall etwas dick, vorn an dem Corpus striatum leicht granulär, am Fornix ebenfalls Flecke, transparente Substanz, namentlich an den hinteren Theilen, besonders neben den Gewölbschenkeln. Beiderseits Vertiefungen von $25 \mathrm{Mm}$. Länge und $3 \mathrm{Mm}$. Breite, auch in der zwisehenliegenden Substanz noch mehrere graue Flecke. Plexus chorioideus etwas roth und dick. Thalami und Corpora quadrigemina ungemein transparent, nur in der Peripherie in unmittelbarem Ansehluss an die Stria cornea weissliche Streifen, an den Corpora quadrigemina nur am vorderen Paar schimmern einzelne weisse Flecke durch, auch an den kleinen Prominenzen der Thalami hie und da ein weisslicher Schimmer. Corpora quadrigemina und thalami weit durchsichtiger und graner, als die oberflächlichen Schichten der Corpora striata, woran nur einzelne, etwas eingesunkene und durchsichtigere Flecke, besonders links, beiderseits ausserdem hinter dem Schwanz an den Ventrikelseitenwänden wieder transparente Flecke, deutlich, etwas eingesunken. Velum medullare etwas transparent, reisst sehr leicht ein. Corpora quadrigemina auf dem Medianschnitt vergrösserte Transparenz. Im 4. Ventrikel gleichfalls Stellen übermässig transparent, zunächst rom Boden des Aquaeductns ausstrahlend, links mehr als rechts, besonders in der Gegend der Substantia nigra, in der Mitte der Rautengrube weisse Substanz, dagegen die Alae cinereae etwas vergrössert durch anschliessende Flecke grauen Gewebes. Wahr- 
scheinlich auch der ganze Calamus scriptorius zu transparent, ebenso die zarten Stränge, während an den seitlichen Theilen der Corpora restiformia wieder weisse Flecke sich zeigen. sonderes.

Auf dem Horizontalschnitt des Kleinhirns nichts Be-

Auf dem Durchschnitt des linken Thalamus zeigt sich die transparente Zone kaum $1 \mathrm{Mm}$. dick, scharf abgegrenat gegen die übrige röthlich grane Substanz, in der Tiefe der Thalami am Linsenkern und Streifenhügel keine Veränderungen. Am rechten Thalamus transparente Schicht nicht so dick und nicht so continuirlich. Centrum semi ovale unverändert, weich, sehr feucht, mässig blutreich. Linkes Ange etwas schlaff. Netzhaut sehr durchsichtig, Papille etwas klein, etwas durchsichtig, sonst an der Netzhaut nichts Besonderes. Opticusscheide weit, Opticus selbst vollkommen transparent und röthlich, nur an einzelnen Stellen weisslicher Schimmer.

d) Ueber den Nystagmus bei Ataxie.

Von Friedreich*) ist eine bestimmte Form zitternder Augenbewegungen, welche insbesondere bei der grauen Degeneration des Rückenmarkes vorkommt, als "ataktischer Nystagmus" beschrieben worden.

Derselbe tritt auf als intermittirender zuckender Nystagmus.

Während der Ruhelage der Augen besteht derselbe nicht; er tritt nur auf, wenn fixirt werden soll.

$\mathrm{Er}$ ist immer bilateral, tritt unabhängig von Sehstörungen auf. und kann in jeder Richtung, der horizontalen, verticalen, diagonalen etc. auftreten.

Ich selbst habe die hierher gehörenden Augenbewegungen einige Male gesehen, in späteren Stadien der Tabes dorsalis und zwar neben Sehstörungen, es liess sich ophthalmoskopisch Sebnervenatrophie verschiedenen Grades nachweisen.

*) Ueber Ataxie (Virchow's Archiv, Bd. 70, 1877.) 
Die zuckenden Bewegungen erfolgten insbesondere beim Wechsel des Blicks, sowie bei Augenbewegungen überhaupt; sie waren nicht immer gleich und wechselten häufig ihre Richtung.

Es unterscheidet sich der atactische Nystagmus daher dadurch vom Nystagmus schlechthin, dass die Augenbewegungen bei ersterem mehr unsicheren, suchenden, gleichsam tappenden Bewegungen gleichen und ihnen der rein rhythmische Charakter im oben definirten sinne in der Regel abgeht. In manchen Fallen würden daher derartige "ataktische Augenbewegungen" den Namen Nystagmus im eigentlichen Sinne nicht verdienen.

\section{Beobachtung 15.}

[Chronischer Alkoholismus mit Ataxie - passagerer zuckender Nystagmus.]

S. J., Pfründner des hiesigen Hospitals, 52 Jahre alt, war früher Commissionair, hat viel dem Alkohol zugesprochen; seit 6 Jahren Schmerzen in den Gliedern gespürt, welche allmälig zugenommen haben - sehr unsicherer Gang - starker Tremor der Hände, des Kopfes, der Lippen, der Zunge etc. rapide Abnahme des Sehvermögens.

März 1874 ist $\mathrm{S}=\frac{1}{5}$, beiderseits Medien klar. Ophthalmoskopisch bereits leichte Verfärbung der Papille und beginnende muldenförmige Excavation zu constatiren.

Pigmente werden noch unterschieden; Gesichtsfeld ist nicht bedentend verengt.

Die Augen führen, wenn der Kranke aufgefordert wird, z. B. nach rechts zu sehen, beiderseits gleiche, zuckende Bewegungen nach rechts aus, es ist dem Kranken nicht möglich, einen nach rechts bewegten Gegenstand ruhig zu fixiren.

Die zuckenden Bewegungen erfolgen nicht streng rhythmisch, sind auch nicht einander gleich, indem auf schwächere Zuckungen öfter stärkere folgen und umgekehrt, und nehmen an Intensität rasch $a b$, bis sie bei unverändertem Blick allmälig schwinden. In Aufregungszusłänden werden die Zuckungen stärker und halten länger an. 
Beim Blick nach oben wechseln Zuckungen nach oben mit soleben in der horizontalen ab.

Beim Blick nach unten entsprechendes Verhalten.

Gegenwärtig nach 2 Jahren ist Patient an Sehnervenatrophie vollständig erblindet, kann sich nur an Krücken bewegen. Bei der Aufiorderung, die Augen zu bewegen, tritt der Nystagmus in beschriebener Form noch deutlich zu Tage.

Friedreich vermuthet als Grund des ataktischen Nystagmus eine Störung coordinatorischer Leitungsbahnen, welche das Cordinationscentrum mit den Kernen der Augenmuskelnerven im Boden des 4 . Ventrikels verbinden. Durch Meynert siud bekanntlich von dem oberen Vierhügel (dem Coordinations - Centrum für die Augenbewegungen) zum Kerne des Oculomotorius und Trochlearis in der Rautengrube ziehende Fasern anatomisch erwiesen. F. nimmt an, dass der Nystagmus erst dann auftrete, wenn der Degenerationsprocess bis zur Medulla oblongata vorgeschritten sei. Mit dieser Annahme stimmt ganz gut das relativ späte Auftreten des Nystagmus, sowie sein Vorkommen- neben Störungen des Sehvermögens, welche meist auf Sehnervenatrophie beruhen.

Nach Pierret*) liegt dem ataktischen Nystagmus eine primäre Erkrankung der sensiblen Bahnen des Trigeminus in der Medulla zu Grunde und wenn wir annehmen, dass sensible Reize auf jenen Bahnen geleitet, auch von der Medulla und dem Halsmark aus auf den Sympathicus übertragen werden and als Reize für die Erweiterung der Iris wirken**), so würde bei einer

*) Pierret, A. (Essai sur les symptomes cephaliques du tabes dorsualis, Paris, 1876.)

**) Vergl. Raehlmann und Witkowski: „Ueber Pupillenenge im Schlafe nebst Bemerkungen zur Innervation der Iris (Archiv für Anatomie und Physiologie. Jahrg. 1878.) 
Beeinträchtigung der sensiblen Leitungsbahnen des Trigeminus freilich anch die Enge der Pupille erklärt sein, welche sich bei ataktischen neben dem Nystagmus bisweilen ausgesprochen vorfindet.

Wie dem auch sein mag, jedenfalls ist der von Friedreich bei Ataxie aufgefundene sog. Nystagmus ein höchst werthvolles Krankheitssymptom und in seiner Bedeutung für das bestehende Centralleiden nicht zu unterschätzen.

Es müsste nun nach dem Gesagten entschieden für einen Mangel an Consequenz erklärt werden, wollte man für manche Fälle von Nystagmus die centrale Ursache bestreiten, weil flagrante Centralerkrankungen fehlen.

Der Nystagmus bei disseminirter Sclerose und bei Hirnerkrankungen überhaupt, unterscheidet sich nach Form und Symptomatologie in nichts Wesentlichem vom Nystagmus überhaupt*); er zeigt dieselbe Abhängigkeit von sensoriellen Einfüssen, von Blickrichtungen etc., kurz es liegt kein Grund vor, denselben vom Nystagmus überhaupt zu trennen, und zwischen einem symptomatologischen und idiopathischen Nystagmus zu unterscheiden, wie es Gadaud in seiner oft erwähnten Arbeit gethan hat.

5. Nystagmus neben ausgesprochenen Ano. malien des Farbensinnes.

Es ist jedenfalls kein Zufall, dass bei vielen Nystagmuskranken Störungen der Farbenempindung vorhanden sind.

In der Literatur finde ich 4 Fälle verzeichnet, in denen Farbenblindheit bei Nystagmuskranken gefunden

*) Während der gewöhnliche Nystagmns constant im Schlafe verschwindet, hört nach Gadaud der bei Hirnkrankheiten vorkommende während des Schlafes nicht auf. 
wurde. Die Fälle finden sich bei Gadaud (l. c.), Boeh $\mathrm{m}^{*}$ ), A. Graefe**) (Fall 18, 1. c.), D. v. Reuss***).

In dem Graefe'schen Falle war absoluter Mangel jeglichen Farbensinnes vorhanden.

Ich selbst habe vollkommenen Daltonismus in zwei Fällen constatiren können, bei Kranken, deren Augen, abgesehen .von dem horizontaloscillirenden Nystagmus, welcher übrigens bei allen Blickrichtungen nahezu derselbe blieb, keine Störungen, weder Trübungen der brechenden Medien, noch Verẫnderungen des Hintergrundes aufwiesen. Das Gesichtsfeld war normal; die Sehschärfe gleich $\frac{1}{3}$ bis $\frac{1}{2}$ der normalen.

Unter den Pigmenten wurden vorzugsweise grün and roth verwechselt. Das Spectrum erschien zweifarbig; das rothe Ende verkürzt.

(Die Fälle werden anderen Orts in extenso beschrieben.)

Interessanter noch sind die zwei nachstehenden Beobachtungen, welche sich auf Personen beziehen, denen jede Farbenempfindung mangelte. Da die Fälle von absoluter Achromatopsie sehr selten sind - die einzigen spectroskopisch genauer studirten Fäle sind von Donders und von mir beschrieben - so ist das Vorkommen neben einer Motilitätsstörung des Auges in zwei Fällen, zu welchen der Graefe'sche Fall als dritter hinzukommt, höchst bemerkenswerth.

*) Boehm, 1. c. Beispiel 5. (Boehm beobachtete an sechs Brüdern neben Nystagmus auch Farbenempfindungsstöruagen. Auf pag. 143 heisst es, dass blau, roth und gelb gefärbte Papiere nur in der Helligkeit der Farben verschiedenen Eindruck hervorriefen.

**) A. Gra ef e. Motilitätsstörungen, 1. c.

***) D. v. Renss. (Ueber den Nystagmus der Bergleute. Gräfe's Archiv, Bd. XXIII. 3., pag. 244). 
Beobachtung 16.

[Nystagmus neben rhythmischen Zuckungen der Lider; beide Bewegungen abhängig von der Belenchtung - absolnte Farbenblindheit.]

S., Amalie, 18 Jahre alt, stammt aus gesunder, zu Nervenkrankheiten nicht disponirter Familie. Eltern leben beide. Geschwister gesund und kräftig; ein jüngerer Bruder leidet wie die Patientin an Nystagmus, sowie an ununterbrochenen Orbiculariszuckungen. - Patientin selbst war stets gesund, hat, so lange sie denkt, immer an den zu beschreibenden Störungen gelitten, ist kräftig gebaut, ohne Constitutionsanomalie. Motilität und Sensibilität normal; Kopfform nicht auffallend.

Bei der oberflächlichsten Betrachtung der Patientin fallen perpetuirliche klonische Znckungen des Orbicularis palpebrarum jeder Seite auf, die nach gewissen Einflüssen, insbesondere sensoriellen, mit verstärkter Intensität anftreten, nie vollständig verschwinden.

Ausser diesen stetigen Lidbewegungen fortdauernder, aber an Intensität wechselnder Nystagmus beider Bulbi. Beim rubigen Blick gerade aus ist der Nystagmus fast 0 ; man bemerkt nur höchst gering - gradige horizontale Vibrationen. Bei Convergenzgraden nimmt der Nystagmus an Intensität zu bis zu einer Convergenz von ea. $10 \mathrm{Cm}$. Ist ein Fixationsobjeet bis auf diese Entfernung den Angen genähert, so hört der Nystagmus wieder fast gänzlich auf. Bei seitlichen Blickrichtungen mit oder ohne Accommodation wird der Nystagmus stärker.

Dio erwähnten Zuckungen im Orbicularis varïren während der beschriebenen Veränderung des Nystagmus durchaus nicht.

Nur bei extremer Senkung des Blickes hört der Nystagmus sowohl, als auch das Zucken der Lider vollständig auf.

Die klonischen Krämpfe der Lider sind am besten bie greller Tagesbelenchtung wahraunehmen; es erfolgen dann 100-150 Zuckungen in der llinute, bei eintretender Dämmerung lassen die Znckungen an Intensität nach, bei Lampenbeleuchtung werden die Augen vollstăndig frei geöfnet und finden keine Zuckungen statt. - Der Nystagmus zeigt ein ähnliches Verhalten.

Bei greller Tagesbeleuchtung ist er am stärksten; bei Lampenlicht hört er vollständig auf. 
Die Kranke giebt entsprechend diesem Verhalten an, dass sie in der Dämmerung und bei künstlicher Beleuchtung sehr viel besser sieht, als am Tage.

Der Nystagmus ist jedoch momentan wieder hervorzurufen, wenn man ein Auge oder beide unverhofft seitlich oder mit einem lichtstarken Spiegel direct beleuchtet, es treten dann vorübergehende Oscillation von ziemlicher Heftigkeit auf. - Beiderseits: alte Hornhautflecke, die ubbrigen Medien der Augen sind klar, im Hintergruade nichts abnormes.

Beiderseits ist $\mathrm{S}=\frac{1}{12}$, Jäger 5 wird in 5 Zoll gelesen, das Gesichtsfeld ist beiderseits frei.

Das Muskelgleichgewicht, so genau es sich bei der vorhandenen Sehschwäche prüfen lässt, ist vollstündig erhalten.

Die Beweglichkeit jedes Auges für sich geprüft, ist intact.

Pigmente werden sämmtlich verwechselt. Das Spectrum erscheint als Lichtstreifen, weiss, ist in der Mitte am hellsten. Alle Farben, isolirt eingestellt, werden als woiss bezeichnet, grün wird dabei immer "am hellsten" empfunden. Die Conjunctiva ist vollständig gesund.

Der erwähnte Bruder der Patientin, welcher wie sie, selbst an Nystagmus und Lidzucken leidet, hat ebenfalls die Farben nie unterscheiden können.

Beobachtung 17.

[Beiderseitiger vertical-oscillirender Nystagmus; klonische Krämpfe des Orbicularis - Abhängigkeit von der Beleuchtung - absolute Farbenblindheit - mittlerer Grad von Blödsinn.]

$R$. Catharina, 15 Jahre alt. In ascendirender Linie keine Heredität nachweisbar. - Ein Bruder soll ebenfalls „mangelhaftes Gesicht" haben, die übrigen Geschwister sind gesund.

Patientin ist normal entwickelt geboren, hat im 2. Lebensjahre an Convulsionen gelitten, welche sich 2 Monate lang fast täglich wiederholten. Die psychischen Functionen zeigten sich frühzeitig bèschränkt. Sie lernte nicht lesen, obwohl sie bis zum vellendeten 14. Lebensjahre Schulnnterricht hatte. 
Von den Angehörigen wurde dem mangelhaften Gesicht und Gehör die Schuld daran beigemessen. Patientin ist zu gröberen Arbeiten im Hause zu verwerthen.

Kleines Individuum mit ungewöhnlich entwickeltem Pannic. adiposus; auffallend stark entwickelte Mammze. Gang eigenthümlich wackelnd; Physiognomie sehr stupid, platte, breite Nasenwurzel, Unterkiefer leicht vorspringend, Ohren sehr klein. Kopf klein, Hinterhaupt schwach entwickelt. Kopfumfang (grösster, Stirn - Hinterhaupt) $52 \mathrm{Cm}$, Fronto-occipital-Durchmesser $17 \mathrm{Cm}$., Riparietal-Durchmesser (breitester des Kopfes) $14 \mathrm{Cm}$., Bitemporal 12,5 Cm.

Kein Tremor der Extremitäten, aber Zittern der Mundwinkel, der Lippen and der vorgestreckten Zunge. Links: hintere Corticalcataract - Conjunctiva gesund, braune Punkte, wahrscheinlich Irispigment auf der Linsenkapsel. Rechts: hintere Corcicalcataract weniger ausgebreitet, als links. Sonst Medien beiderseits klar, Hintergrund, soweit er sich übersehen lässt, gesund, kein Pigment in der Retina. Pupillen reagiren gut.

Es besteht Myopie mittleren Grades. Der Grad wegen Unruhe der Patientin nicht zu bestimmen. - Mit einem Convavglase - 7 Diopt. werden Finger beiderseits in 8-10 Fuss Abstand richtig gezählt - Gesichtsfeld ist ebenfalls nicht genau zu prüfen, es scheint nicht beschränkt zu sein. - Alle Pigmentfarben werden verwechselt - Patientin hält unter diversen, von mir vorgelegten Papieren:

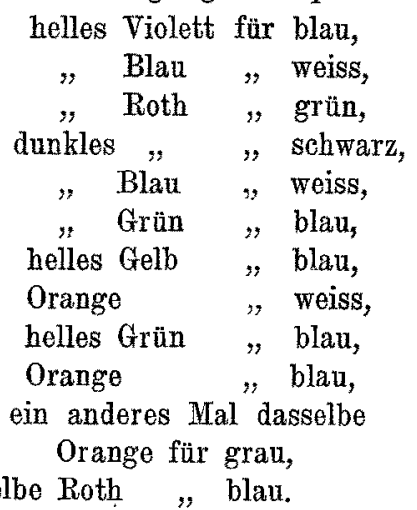

Es unterliegt nacb diesen Prüfungen wohl keinem Zweifel, dass die Patientin an absolutem Mangel jedes Farbensinnes leidet, und nur den einzelnen Farben Namen 
gibt, welche sie von ihrer Umgebung gelernt, mit denen sie jedoch wohl keine Begriffe verbindet. Auf die zurückgebliebene geistige Entwicklung kann der Mangel der Farbenunterscheidung nicht zurückgeführt werden, da Leute mit viel weniger entwickelten Fähigkeiten, ja selbst Idioten, welche nur ganz leichte Sätze verstehen, die Lichtqualitäten gut differenziren und in der Regel auch richtig benennen.

Continuirliche klonische Zuckngen im Orbicularis beiderseits, welche vollständig rhythmischerfolgen, Bei diffuser Tagesbeleuchtung, im Zimmer, werden deren an 150 wăhrend der Minute gezählt, wird die Patientin in ein mit Lampen- oder Gaslicht erhelltes Zimmer geführt, so lässt die Anzahl der Zuckungen bedeutend nach; es erfolgen ca. 15 in der Minute. Die Kranke giebt selbst an, dass sie des Abends im Dunkeln oder im von der Lampe erhelltem Zimmer die Augen freier öfnen kann.

Perpetuirlicher, vertical-oscillirender Nystagmus, der bei allen Blickrichtungen annähernd mit gleicher Intensität fortdauert, aber bei künstlicher Beleuchtung an Stärke nachlässt.

Es wäre hier noch schliesslich auf die Beobachtung 18 zu verweisen.

C. Besondere Abhängigkeitsverhältnisse des Nystagmus.

1) Ueber den Einfluss der Willkür auf den Nystagmus.

Nicht immer stellt der Nystagmus unwillkürliche Augenbewegungen dar, sondern in einzelnen Fällen werden diese Bewegungen vom Willensact vollständig beherrscht, so dass sie von dem Patienten beliebig hervorgerufen und unterdrückt werden können.

Von der augenblicklichen Augenstellung resp. Blickrichtung ist in solchen Fällen die Möglichkeit, den Nystagmus hervorzubringen, durchaus unabhängig; er tritt nur ein nach Massgabe der einfachen Willensbestimmung der Patienten. 
$\mathrm{Zu}$ bemerken wäre, dass in den zwei Fällen, die ich nachstehend beschreibe, der Nystagmus in dex Kindheit fortdauernd bestanden hat, sich dann später verlor, von dieser Zeit an aber jederzeit willkürlich reproducirt werden konnte.

Bevor ich die von mir beobachteten Fälle ausfübrlich beschreibe, möge der einzige in der Literatur vorhandene Fall aus Fano (traité des maladies des yeux, T. II, p. 660) wörtlich citirt worden.

„Plauté étudiant en médecine, age de 25 ans. - Il y a environ dix ans (1855), alors que j'étais au collége, je me suis aperçu pendant une récréation, en fixant un objet que mes yeux tremblaient dans l'orbite et que tout ce, qui était compris dans le champ de ma vision, oscillait avec une vitesse assez grande. Pour la euriosité du fait, et afin de le montrer à mes camarades, j’ai essayé de reproduire ce tremblement, et à ma volonté cette contraction des muscles de l'oeil a recommencé. Depuis cette époque, il m'arriva très-souvent de faire constater ce phénomène. Il me suffit pour cela d'ourrir un peu fortement les yeux de regarder fixement devant moi, et la contraction a lieu. Le globe s'agite en se portant de droite à gauche et de gauche à droite, et ainsi de suite. Le mouvement commence de mème, qu'il cesse brusquement et sans efforts, anssitôt, que je le venx. Que ce Nystagmus dépendant de ma volonté, je le répète souvent ou peu, je n'éproure à la suite aucune fatigue, aucun trouble du côté de la vision. Du reste ma vue a toujours été excellente."

\section{Beobachtung 18.}

[Willkürlicher Nystagmus in horizontalen Oscillationen - Muskelgleichgewicht, normale Sehschärfe - Daltonismus.]

Hr. Dr. S., prakt. Arzt, wurde vor 3 Jahren wegen Daltonismus ron mir untersueht.*) Die Augen des Herrn S. sind emmetropisch gebaut. Die Sehschärfe, sowie die Accommodation

*) Rücksichtlich der Farbenempfindung des Patienten vergl. Raehlmann. (Ueber den Daltonismus u. die Young'sche Farbentheorie v. Graefe's Arch., Bd. XXII, 1., p. 34.) 
waren normal, das Gesichtsfeld hatte normale Grenzen. Bei einer genauen Untersuchung der Beweglichkeit der Augen zeigen sich vollkommen normale Verhaltnisse. Auch das Muskelgleichgewicht, nach derv. Graefe'schen Methode geprüf, ist in allen Fixationslagen erhalten. Herr S. überwindet für $\infty$ ein Prisma von $5^{0}$ durch facultative Divergenz. Für 10" Abstand das Prisma von $32^{\circ}$ durch Adduction.

Unter den Pigmentfarben wurden besonders Roth und Grün verwechselt. Das zweifarbig erscheinende Spectrum war am violetten Ende erbeblich verkürzt. Das Maximum der Empindlichkeit der Netzhaut bestand für Gelb; für Grün war dieselbe gegenüber der Empfindlichkeit des Normalauges beträchtlich gesunken.

In der Familie des Herrn S. finden sich äbnliche Anomalien des Gesichtssinnes nicht; auch kein Fall von Nystagmus ist in derselben vorhanden.

Herr S. hat als Kind beständig an Nystagmus gelitten, der sich bei Gemüthsbewegungen etc. verstärkte, zu Sehstörungen jedoch - soviel Patient sich erinnert - niemals Veranlassung gegeben hat. Gegen das 15. Lebensjahr hat der Nystagmus an Intensität verloren, ist dann nur periodenweise aufgetreten und zwar meist nur bei besonderen sensoriellen Erregungen und hat sich endlich ganz verloren. Herr $\mathbf{S}$. hat jedoch während seiner Gymnasialzeit seine Mitschüler oft dadurch ergötzt, dass er die Nystagmusbewegungen willkürlich horvorbrachte und beliebig lange unterhielt. Die Möglichkeit dieser Willkürbewegungen ist auch heute noch vorhanden. Der Nystagmus in Form horizontaler, ansserst lebhafter Oscillationen kann bei jeder Stellung der Blicklinien hervorgebracht werden. Nur bei änsserster Convergenzstellung auf $7-10 \mathrm{Cm}$. und näher ist er nicht möglich.

Es können während der Dauer des Nystagmus Gegenstände fixirt werden, dieselben scheinen sich jedoch in horizontalen Excursionen zu bewegen; und diese Excursionen sind bei känstlicher Diplopie nach Prismavorlage beiderseits vollständig gleich. 


\section{Beobachtung 19.*)}

[Willkürlicher Nystagmus - Muskelgleichgewicht.]

V., Marie, 17 Jahre alt, Findelkind aus Strassburg; hat die gewöhnlichen Kinderkrankheiten durchgemacht, ist sonst gesund gewesen. Vollständig normal entwickeltes Mädchen Ansehwellung der Hals-, Nacken- und Achseldrüsen - keine nerrösen Symptome.

Hat früher viel an Conjunctivalentzündungen gelitten.

Beiderseits alte Hornhantflecke, welche die Pupille zum Theil bedecken, die Augenmedien sonst klar.

Die Sehschärfe beiderseits noch fast $\frac{1}{2}$ der Normalen. J. 1 wird in $8^{\prime \prime}$ Entfernung fliessend gelesen. Gesichtsfeld frei. Farbenunterscheidungsvermögen gut. Beweglichleit beider Angen ist vollständig normal; der binoculare Sehakt in allen Theilen des gemeinschaftlichen Blickfeldes erhalten.

Das stereoskopische Sehen ist normal. Die Fusionstentenz gegenüber Prismen verschiedenen Grades ist ziemlich erheblich; es besteht bei Vornahme des v. Graefe'schen Gleichgewichtsversuches keine latente $\mathrm{Ab}$ weichung. Bei Vorlage eines Prisma mit der Basis oben steht das obere Bild vertical über denı unteren.

Für die Ferne besteht eine facultative Divergenz von $8^{\circ}$ Prisma, eine facultative Convergenz $=28^{\circ}$. Für $10^{\prime \prime}$ Abstand ist die facultative Convergenz $=38^{\circ}$, die facultative Divergenz $=26^{\circ}$ Prisma.

Die Patientin hat in früher Jugend an Nystagmus gelitten, derselbe ist schon seit Jahren verschwunden, kann aber jederzeit willkürlich von der Patientin hervorgebracht werden. Dass dieser willkürhiche Nystagmus nicht peripheren Ursprungs ist, etwa dureh bestimmte Stellung des Auges in Folge besonderer Muskelthätigkeiten hervorgebracht wird, folgt daraus, dass derselbe bei jeder Stellung der Angen in gleicher Weise möglich ist. Sowohl bei Convergenz als bei Parallelstellung, sowohl bei gehobener, als bei gesenkter Blickebene kommt der Nystagmus zum Vorschein, sobald die Patientin will. Dabei wird Scheinbewegung der fixirten objecte wahrgenommen.

*) Die Patientin ist von mir in der Februar-Sitzung (1878) der naturwissenschaftlich-medizinischen Gesellschaft in Strassburg demonstrirt worden. 
Aus diesen Beobachtungen von willkürlichem Nystagmus geht mit Bestimmtheit hervor, dass als Grund desselben centrale Vorgänge anzusprechen sind, welche für gewohnlich der Willkür entzogen sind, in einzelnen Fällen ihr dienstbar werden können. Es ist wohl kein Zweifel, dass in den zwei vorstehend beschriebenen Fällen die Patienten von der Kindheit her, in welcher der $\mathrm{Ny}$ stagmus permanent bestand, ein bestimmtes psychisches Bewusstsein jener centralen Vorgänge auch nach dem Verschwinden des Nystagmus behalten haben, und durch Reproduction bestimmter indefinirbarer Willensenergien jene Vorgänge wieder vorübergehend hervorzubringen verstehen.

2) Ueber die Abhängigkeit des Nystagmus vom Binocularsehen.

a. Der Nystagmus findet sich sehr oft noch ausgesprochen an völlig erblindeten Augen vor; er ist also in diesen Fällen vom Binocularsehen, vom Sehakte überhaupt, ganz unabhängig.

Beobachtung 20.

[Zuckender Nystagmus - atypische Augenbewegungen -

Amaurosis absoluta.]

S., Jeanne, 18 Jahre alt, befindet sich seit längerer Zeit wegen Schwachsinns mit Aufregungszuständen in der Irrenanstalt Stephansfeld. Beiderseits Amaurosis absoluta. Spannung der Bulbi sehr herabgesetzt. Rechts totales Leucom, fast die ganze Cornea einnehmend. Links Leucoma adhaerens (iridectomirt nach Innen). Die Bulbi machen, wenn die Patientin aufgefordert wird, die Augen nach einer bestimmten Seite zu bewegen, eigenthümliche, incoordinirte Bewegungen, wobei die verschiedensten Schielstellungen eingeleitet werden. Dabei besteht zuckender Nystagmus, der auch in vermindertem Grade noch fortdauert, wenn keine Augenbewegungen vorgenommen werden. Die zuckenden Bewegungen erfolgen meistens in der 
Richtung der intendirten Bewegung, die Augen bewegen sich dann langsam entgegengesetzt dieser Richtung zurück.

Es erfolgen 80-120 Zuckungen in der Minute, in Aufregungszuständen werden dieselben stärker und frequenter. Bei Streichen der Wangen und Unterkiefergegend werden constant Augenbewegungen, begleitet von dem in gleicher Richtung zuckenden Nystagmus nach unten und entsprechend rechts oder links hervorgerufen. Ebenso regelmässig treten bei Streichen der Schläfengegend die analogen Augenbewegungen nach oben rechts resp. links ein, der zuckende Nystagmus verhält sich dabei in angedenteter Weise.

In anderen Fällen jedoch zeigt der Nystagmus eine unverkennbare Abhängigkeit vom Binocularsehen.

Bisweilen wird diese Abhängigkeit schon dadurch erwiesen, das einfach das Verdecken eines Auges genügt, um den Nystagmus hervorzubringen resp. zu verstärken. (Man vergl. die Fälle $10,11,12$ und 18 bei $A$. Graefe [l. c.], sowie den 2. Fall von Baumeister*), ferner Fancou. ${ }^{* *}$ )

Seltener scheint die Abhängigkeit nur an die Fixation eines Auges allein gebunden zu sein, wie bei dem Fall 10, 12 und 18 bei $A$. Graefe.

Das Verdecken eines Auges kann aber auch den ganz entgegengesetzten Effect haben und den Nystagmus zum Stillstand bringen, resp. seine Intensität vermindern, wie es z. B. in unseren. Beobachtungen 3 und 21 der Fall war.

Aber abgesehen von dem Effecte der direkten Unterbrechung der binocularen Fixation sind auch die besonderen Accommodations- und Convergenzvorgänge bei binoculärer Einstellung in vielen Fällen für den Nystag* mus massgebend.

*) Baumeister, E., Graefe's Archiv, Bd. XIX, 2, p. 267.

**) Faucou (Nystagmus par insuffisance des droits externes Journal d'ophth., p. 233 u. f.). 
Die Einleitung künstlicher Diplopie kann den $\mathbf{N y}$ stagmus verstärken. (Graefe, l. c.)

Ungewöhnlich oft hört der Nystagmus gänzlich auf, wenn hohe Convergenzgrade gegeben sind. (Man vergl. den 2. Fall von Schroeter*) und bei A. Graefe die Fálle 5-9, sowie unsere Beobachtungen 4, 16, 18, 21, 22 und 26.)

Beobachtung 21.

[Erworbener einseitiger Nystagmus, abhängig von der Beschattung des gesunden Auges und von der Convergenz.]

H., Ilarie, 21jährige Lehrerin, aus gesunder Familie, sah mit dem linken Auge von jeher schlecht, schielt seit dem 7. Jahre mit dem linken Auge, wurde vor 2 Jahren wegen linksseitigem Strabismus convergens beiderseits durch Tenotomie operirt. Die mittlere Stellung der Augen war nach der Operation befriedigend; von Nystagmus war keine Spur vorhanden.

Gegenwärtig stellt sich die Patientin wieder vor mit einem Strabismus divergens des linken Auges von ca. $5 \mathrm{Mm}$. Augenmedien beiderseits klar. Rechts besteht Em. $\mathrm{S}=1$. Links starke Amblyopie (Finger in 6-8') ohne ophthalmoskopischen Befund. Gesichtsfeld auch links frei. Es besteht perpetnirlicher Nystagmus des linken Auges in Form verticaler Oscillationen. Dieselben sind am stärksten beim Blick geradeaus, bei Seitenwendungen wird der Nystagmus sehwächer; in ganz extremer Seitenstellung der Augen hört er ganz auf; dasselbe gilt von Hebungen nnd Senkungen der Blickebene. Die Oscillationen erfolgen ungefähr 90-110 in der Minute.

Bei Annäherung eines Fixationsobjectes hört der Nystagmus bei ca. $70 \mathrm{~cm}$. Entfernung vollständig anf und ist überhaupt bei keiner Stellnng der Augen während der Fixation für die Nähe vorhanden.

Der verticale Nystagmus des linken Auges hört auf, wenn das rechte Ange mit der Hand bedeckt wird; die Bedeckung des linken hat keinen Einfluss.

*) Schroeter, Dr. Paul (2 Fälle von Nystagmus bei Berglenten. Klinische Monatsblätter für Augenheilkunde, Bd. IX, p. 135, J. 1871.) 
Beobachtung 22.

[Einseitiger Nystagmus - verticale Oscillationen - abhängig von der Convergenz sowie von Blickrichtungen.]

B., Louise, 15 Jahre alt, aus Strassburg. Rechts H. 0,75 D. $\mathrm{S}=1$. J. Nr. 1 wird bis $2 \mathrm{~W}_{2} "$ gelesen. Links linsengrosses Leucom, welches die Pupille bedeckt. S gleich Handbewegungen in nächster Nähe.

Patientin stammt aus gesunder zu Nervenkrankheiten nicht disponirten Familie, war in der Kindheit gesund. Der Hornhauttleck des linken Auges soll im 4. Jahre der Patientin während der Pocken entstanden sein.

Leichte Divergenzstellung des linken Auges. Bewegungsexcursionen des Bulbus links wie auch rechts vollkommen ausgiebig möglich.

Oscillirender Nystagmus des linken Auges in verticaler Richtung, während das rechte vollkommen still steht. Die Bewegungen sind in der Primärlage, wenn das rechte Auge in die Ferne sieht, verhältnissmässig stark, bei starker Seitenwendung nehmen sie $a b$, werden kaum bemerkbar; beim Blick nach unten hören sie vollständig auf und zwar ebensowohl beim Blick nach reehts, als nach links unten. Beim Blick nach oben nehmen die Bewegungen an Intensität za, und zwar sind sie am stärksten bei einer Elevation von $20^{\circ}$; beim Blick nach oben und gleichzeitiger Seitenwendung bestehen die Oscillationen etwas langsamer fort.

Bei Convergenz nimmt anfangs die Stärke des $\mathrm{Ny}$ stagmus zu bis auf ca. 7" Entfernung. Bei stärkerer Annäherung des fixirten Gegenstandes nimmt der $\mathrm{Ny}$ stagmus wieder ab und wird bei einer Annaherung auf 2/2 Zoll gleich 0 .

b. Der Nystagmus zeigt ferner eine seit langer Zeit bekannte Abhängigkeit von der Einhaltung bestimmter Blickrichtungen. Man trifft selten Fälle, bei denen diese Abhängigkeit sich nicht in irgend einer Stellung nachweisen liesse. In einer grossen Anzahl von Erkrankungsfällen wird der Nystagmus stärker, wenn der Blick gehoben wird. (Vergl. Graefe: Fall 14, 18, unsere Beobachtung 20. 
Es kann sogar der Nystagmus in allen anderen Lagen der Blickebene vollständig feblen und nur bei gehobenem Blick hervortreten.

Beobachtung 23.*)

[Einseitiger Nystagmus, abhängig von Blickrichtungen.]

G., Felix, 7 Jahre alt, aus Paris.

L.: kleiner Hornhautfleck nach Innen vom Centrum mit vorderer Synechie. Einseitiger Nystagmus des linken Auges (Rotationen des Bulbus), bei den Bewegungen nach aussen oben.

Bei dem Nystagmus der Bergleute ist, wie aus den ubereinstimmenden Beschreibungen fast aller Autoren hervorgeht, das letztere Verhalten fast durchgängig ausgesprochen.

Eine ähnliche Abbängigkeit zeigt der Nystagmus in sehr vielen Fällen bei seitlichen Blickrichtungen. Doch ist die Behauptung Gadauds: "l'augmentation du nystagmus a également lieu dans la fixation latérale forcée", entschieden übertrieben.

Es giebt Fälle, wo der Nystagmus fortdauernd besteht, aber beim Blick nach jeder oder auch nur nach einer Seite constant aufhört und umgekehrt kommen nicht selten Falle vor, in denen die Augen nur bei seitlichen Blickrichtungen den Nystagmus zeigen; in allen anderen Stellungen aber vollständig in Ruhe verharren. (Man vergl. bei Boehm den Fall XIV, ferner Nr. 1, 2, $3,4,18$ bei A. Graefe, dann die Fälle von Baumeister und Taucou, l. c.)

Man darf jedoch nicht glauben, dass es immer dieselben seitlichen Blickrichtungen sind, bei welchen der Nystagmus auftritt resp. sich vermindert; vielmehr lebrt die Beobachtung, dass bei ein und derselben Person bald

*) Ich verdanke die Mittheilung dieses Falles der Güte des Herrn Prof. Laqueur. 
beim Blick nach rechts nicht aber nach links, bald aber umgekehrt beim Blick nach links und nicht nach rechts die erwähnte Abhängigkeit hervortritt. Dieses Verhalten ist für die Frage nach der Ursache des Nystagmus besonders wichtig.

In seltenen Fällen wird der Nystagmus nur nach sehr raschen brüsk erfolgenden Augenbewegungen vorgefunden, während er für gewöhnlich vollständig fehlen kann.

Beobachtung 24.

[Passagerer Nystagmus nur nach brïsken Angenbewegungen auftretend.]

S., Stephanie, 18 Jahre alt, Strassburg. Beiderseits Emmetropie; Sehschärfe, Accommodation, Gesichtsfeld normal.

Bei Vornahme des sog. Graef e'schen Gleichgewichtsversuchs zeigt sich für $10^{\prime \prime}$ Entfernung keine Spur von Insufficienz, für die Ferne ist eine geringe Insufficienz von ca. $5^{0}$ Prisma rorhanden.

Die facultative Divergenz für $\infty$ beträgt $8^{\circ}$. Die facultative Convergenz für $10^{\prime \prime}$ ist $=28^{\circ}$ Prisma.

Conjunctivalhyperaemie, geringe Liehtscheu! Wird die Lidspalte gewaltsam geöffnet, so zeigen sich zitternde Bewegungen der Bulbi (horizontale Oscillationen), welche einige Sekunden in äusserst raschem Tempo anhalten und dann vollständig verschwinden. Dieselben Nystagmusbewegungen treten ein, wenn die Augen rasch zur Seite bewegt oder aus seitlichen Stellungen rasch in die mittlere Ruhestellung zurückgeführt werden.

Sie sind auch beim raschen Blick nach unten besonders stark wahrnehmbar. Während des Bestehens dieses vorübergehenden Nystagmus nach starkem, brüskem Wechsel des Blickes, wird mitunter leichtes Irisschlottern bemerkt. Die linse ist nicht luxirt. Der intraoculare Druck ist dabei, soweit es die Palpation ergiebt, nicht merklich verändert.

Beobachtung 25.

[Nystagmus, abhängig von Blickrichtungen - Strabismus.]

F., Dorothea, 23 Jahre alt, aus Illkirch, stammt aus gesunder zu Nervenaffectionen nicht disponirten Familie. Die 
Patientin hatte als Kind beiderseits Cataract, welche von den Eltern 8 Tage nach der Geburt entdeckt warde. Im Alter von $3 / 4$ Jahren wurde Patientin beiderseits mittelst Discision operirt. Sie hat dann das rechte Auge gebrauchen gelernt. Links ist niemals nennenswerthes Sehvermögen verhanden gewesen.

Schon am Kinde in der Wiege bemerkten die Eltern zitternde Bewegungen der Bulbi.

Rechts Hyperm. $=9$ Dioptr. Sehschärfe $=\frac{1}{5}$ der Normalen, Gesichtsfeld frei. Farbenperception vollständig normal.

Links starke Amblyopie. Sehschärfe gleich Finger in 2 Abstand.

Leichter Grad von Strabismus div. des linken Auges in der Ausgangsstellung, der sich bei verschiedenen Blickrichtungen verstärkt resp. vermindert, oft gänzlich verschwindet, sogar in leichte Convergenzstellung übergeht beim Blick nach links. Keine Beweglichkeitsbeschränkung des linken Auges.

Rechte Pupile beinahe vollständig schwarz. Bei Erweiterung derselben werden in der Peripherie Linsenreste sichtbar. - Ophthalmoskopischer Befund normal.

Links: stark geschrumpiter Nachstaar, dureh dessen mittlere Parthie der rothe Ton des Augenbintergrundes durchscheint.

Wenn die Patientin ruhig ist und vor sieh hinsieht, ist der Nystagmus sehr gering; es finden dann nur rotirende $\mathrm{B} \theta-$ wegungen in zuckendem Tempo statt (entgegengesetzt wie der Uhrzeiger). Sobald die Patientin etwas fixirt, $a$. $h$. sobald man ihre Aufmerksamkeit erregend, eine veränderte Blickrichtung fordert, treten horizontal zitternde Bewegungen auf, die insbesondere, wenn Patientin ängstlich oder aufgeregt wird, an Intensitat so sehr zunehmen, dass dio Bulbi unausgesetzt in grossen Excursionen rythmisch hin und her schwanken.

Die Bewegungen geschehen dann in der Regel so, dass zunächst eine starl zuckende Rollbewegung in etwas langsamem Tempo gemacht wird und dann zwei oder drei horizontale Oseillationen folgen. In dieser Weise dauert das Bewegungsphänomen unausgesetzt fort, bis nach kürzerer oder längerer Zeit die Augen sich wieder beruhigen. 
In manchen Fällen mag in der That, wie es die meisten Autoren auch annehmen, die Augenstellung als solche, $d . h$. eine bestimmte funktionelle Thätigkeit der Augenmuskelgruppen den veränderten Grad des Nystagmus bei seitlicher Blickrichtung bedingen.

Der Meinung Gadaud's jedoch, welehe auch $T$ a u cou theilt, dass eine Uebermüdung des Muskeln den Nystagmus bei bestimmten, besonders den seitlichen Blickrichtungen bewirke, muss ich nach meinen Erfahrungen, gestützt auf viele direkte Gleichgewichtsprüfungen, entschieden widersprechen. Für viele Fälle lässt sich ausserdem direkt nachweisen, dass der Einfluss der seitlichen Blickrichtungen sich auf die Verhältnisse des Binocularsehens zurückführen lässt und die letzteren, wie oben erwähnt, den Nystagmus provociren.

So lange der fixirte Gegenstand sich im Bereiche des gemeinschaftlichen Blickfeldes befindet, also während binocularer.Fixation, besteht in solchen Fällen der Nystagmus nicht; derselbe beginnt erst, wenn beim Blick zur Seite das fixirte Object dem Bereiche des einen Blickfeldes entschwunden ist. Oder die Sache verhält sich umgekehrt; beim binocularsehen besteht Nystagmus und hört bei seitlicher Blickrichtung, wenn monocular fixirt werden muss, vollständig auf. (Beobachtung 3.)

Faucon*) selbst beschreibt seine Fälle ganz typisch. Der Nystagmus betrifft einen geistig beschränkten Sol: daten. Bei binocularer Fixation besteht kein Nystagmus, nur, wenn bei Wendungen der Augen nach rechts und links, das Gesichtsobject nur mehr mit einem Auge fixirt werden kann, tritt der Nystagmus auf; es erfolgen dann 140 bis 150 Zuckungen in der Minute.

Die Abhängigkeit des Nystagmus vom binocularen

*) Faucon, 1 . 
Sehakt zeigte sich im selben Falle noch besonders dadurch, dass auch bei ruhigem Blick sofort Nystagmus auftrat, wenn das eine oder das andere Auge mit der Hand bedeckt wurde und doch sucht $F$, weil sich gleichzeitig eine Beweglichkeitsbeschränkung des externus nachweisen liess, den Grund des Nystagmus in einer Insufficienz der Externi. - In unserem Falle 3 liess sich bei seitlicher Blickrichtung das Aufhören des Nystagmus an der Grenze des einen Blickfeldes genau durch Messung controliren. Sobald der Pupillarrand des einen Auges hinter dem Nasenrücken verschwand, hörte der Nystagmus auf. Auch in diesem Falle wurde der letztere durch Ausschaltung des einen Auges mittelst der deckenden Hand bedeutend vermindert.

3) Ueber die Abhängigkeit des Nystagmus von der bestehenden Sebschärfe.

Die mit Nystagmus behafteten Augen haben oft trotz den steten und raschen Bewegungen eine ganz oder doch fast ganz normale Sehschärfe. (Man vergl. bei A. Graefe die Fälle 1, 12 und 13.)

Beobachtung 26.

[Nystagmus, abhängig von Blickrichtungen und von Convergenzzuständen - Kopfwackeln - normale Sehschärfe.]

H., Joseph, 40 Jahre alt, leidet an Epilepsie mit hochgradigen Aufregungszuständen - starker Tremor des Kopfes (Kopfwackeln), ebenso der Hände, so dass der Patient nicht im Stande ist, ein mit Wasser gefülltes Glas zu halten, ohne davon auszuschütten.

Rechts phthisischer Stumpf; Cataract; Pupillarverschluss, kein Lichtschein.

Links Myopie geringen Grades; S nahezu normal. Der Kranke liest Jäger Nr. 1 in 12“ Entfernung. Augenhintergrund, soweit zu sehen, normal - Gesichtsfeld frei.

Während der Ruhelage der Augen, d. h. beim Blick in die Ferne, leicht rotirender und gleichzeitig horizontal zuckender 
Nystagmus. Gewöhnlich wechseln 2-3 Rollungen mit einer zuckenden Bewegung in der horizontalen ab. Bei Bewegung der fixirten Gegenstände zur Seite findet eine bedeutende Vermehrung der Intensität des Nystagmus statt. Dasselbe ist der Fall beim Blick nach oben. Bei der Blickrichtung nach unten wird der Nystagmus sehr gering, hört aber nicht ganz auf.

Wird aber ein Gesichtsobject in der Medianlinie genähert, so hört der Nystagmus bei einer Convergenz auf 3 " und näher vollstanig auf. - Trotz dieser hinsichtlich des Nystagmus günstigen Stellung wird beim Lesen

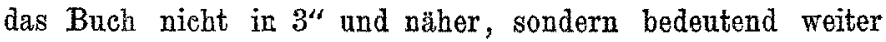
gehalten und während des Nystagmus fliessend gelesen.

Es ist besonders interessant, dass in diesen, wie in anderen Fällen, trotz der stetigen raschen Bewegung der Augen normale Sehschärfe besteht. - Obschon das Retinabild in der Bahn des Nystagmus seinen Ort stetig ändert, also eine Reizung von bestimmter Quantität und bestimmter Qualität mit grosser Schnelligkeit ihren Ort wechselt, reicht dieselbe dennoch nicht allein zur richtigen Orientirung der Retina vollständig aus, sondern es wird dieselbe auch annähernd mit derselben Genauigkeit vom Sensorium empfunden, wie sie vom ruhenden Auge percipirt werden würde. - Es liegt in der Geschichte dieser Fälle darum ein weiterer Beitrag begründet für die Lehre von der Empirie der Sinneswahrnehmungen.

Leicht verständlich ist jedoch die Thatsache, dass in einzelnen Fällen eine Herabsetzung der Sehschärfe mit oder ohne greifbare Veränderungen der Augenmedien oder des Hindergrundes, direkt auf den bestehenden $\mathrm{Ny}$ stagmus als Ursache zuräckgeführt werden kann, indem in einzelnen Stellungen der Augen, bei welchen der Nystagmus aufhört, die Sehschärfe gleichzeitig sich bedeutend bessert. Sebr lehrreich sind in dieser Beziehung die von Baumeister*) mitgetheilten Fälle. - In solchen

*) Baumeister, E. (Einfluss der Kopfhaltung auf die Sehschärfe bei Nystagmus. Graefe's Archiv, Bd. XIX, 2, pag. 267.) 
Fällen pflegen die Kranken sich bestimmte Kopfhaltungen anzugewöhnen welche rücksichtlich der Abhängigkeit des Nystagmus von den Augenstellungen als die vortheilhaftesten erkannt worden sind.

Man hat auch behauptet, dass die Sehschwäche bei Nystagmus an der Entwickelung der Bewegungsanomalie schuld sei, indem dieselbe im frühesten Kindesalter ,das Erlernen einer genauen Fixation" verhindere (Kugel, Narkouz, A. Graefe.)

Wenn ich nun auch die Möglichkeit eines gewissen Einflusses vorhandener. Sehstörungen auf das Zustandekommen des Nystagmus nicht läugnen will, so kann ich doch das causale Verhältniss derselben in der Weise wie die genannten Autoren nicht zugeben, vornehmlich aus dem Grunde, weil sich meistens nachweisen lässt, dass die Sehschärfe ganz ebenso wie der Nystagmus auf Grund derselben Anomalie zu Stande kommt und beide, Sehschwäche und Nystagmus, eine gemeinsame Ursache haben.

So verhält es sich, wie bereits oben (pag. 245) des Näheren erwähnt, bei Microphţhalmos, bei Schicht- und Corticalstaaren, bei retinit. pigm. u. s. w.

Bisweilen ist jedoch die Beziehung des Nystagmus za vorhandener Sehschwäche dadurch ausser Zweifel gosetzt, dass derselbe mit der Sehstörung entsteht und schwindet.

\section{Beobachtung 27.}

[Zuckender Nystagmus, abhängig von Blickrichtungen - Entstehung gleichzeitig mit pannöser Keratitis - Aufhören des

Nystagmus nach Wiederherstellung des Sehvermögens.]

$\mathrm{K}$, Magdalene, 50 Jahre alt, aus Rheinzabern. Schwachsinnige, unreinliche, schwatzhafte Person, welche angiebt, seit 18 Jahren schlecht zu sehen. Seit den letzten zwei Jahren keine weitere Abnahme des Sehvermögens.

Beiderseits narbige Streifen in der Conjunctiva in Folge abgelaufenen Trachoms, stark ausgesprochene pannöse Trübungen 
der Cornea, links ausserdem stecknadelknopfgrosse, umschriebene Cornealnarbe mit Adhaerenz eines kleinen Theiles des Pupillarumfanges. Das Sehvermögen bis auf Fingerzầhlen in ca. $12^{\prime}$ Entfernung beiderseits vermindert. Nystagmus. Nach Angabe der Patientin soll derselbe seit zwei Jahren bestehen.

Beim Blick in die Ferne zuckende Bewegungen beider Bulbi meistens nach links, bisweilen auch nach rechts.

Dieselben erfolgen in rhythmischer Reihenfolge, wenn die Patientin ruhig ist, ungefähr 80 bis 120 in der Minute. Wird die Patientin angstlich oder aufgeregt, steigert sich die Frequenz der Zuckungen ganz erheblich. - Beim Blick nach rechts sind die Zuckungen in der Regel stärker, als beim Blick nach links, oft ist auch das Umgekehrte der Fall.

Beim Blick nach oben erfolgen constant stärkere Bewegungen! - Beim Blick nach unten relative Ruhe.

Nach vierwöchentlicher Behandlung, nachdem in Folge der Rückbildung des Pannus das Sehvermögen erheblich gebessert, ist der Nystagmus verschwunden.

Die Behauptung Kugel's*), dass bei Nystagmus stets verminderte Sehschärfe besteht, bedarf nach dem oben Gesagten keiner Widerlegung; auch kann ich der Meinung desselben Autors, dass bei Nystagmus beide Augen meist dieselbe Sehschärfe haben, nach meinen Erfahrungen nicht beistimmen.

4. Ueber die Abhängigkeit des Nystagmus von der äusseren Belenchtung im Allgemeinen und von dem Nystagmus der Bergleute im Besonderen.

Dass die Intensität der Beleuchtung auf den Nystagmus Einfluss hat, wurde bereits früher, bei Besprechung der den Nystagmus häufig begleitenden Lidzuckungen des Näheren erwähnt. - Schon Boehm**) hat diese Ab.

*) Kugel, Dr. L. Vorläufige Notiz über Nystagmus. Graefe's Archiv, Bd. XIII. 2, pag, 413.

**) Boehm, 1. c., pag. 65 . 
hängigkeit hervorgehoben, er glaubt, dass „mit der Verminderung des einströmenden Lichtes sich die Zuckungen der Aungen im umgekehrten Verhältnisse beflügeln" und er leitet diese "schädliche Rückwirkung aus der gesteigerten Unthätigkeit der beschatteten Augen" ab. So einfach liegt jedoch die Sache leider nicht. In manchen Fällen bringt die gewöhliche Dämmerungsbeleuchtung am Abend eine Verminderung des Nystagmus, in anderen Fällen eine Vermehrung desselben hervor. - In den vorstehend beschriebenen Krankengeschichten (Beobachtung 2, 6, 16 und 17) ist bereits hervorgehoben, dass auch die künstliche Beleuchtung (Kerzen- oder Lampenlicht, Gaslicht) in nicht zu greller Intensität verwandt, einen ganz ähnlichen Einfluss ubt, als das abgeschwächte Tageslicht, und in einzelnen Fällen den Nystagmus vermehrt, in anderen denselben vermindert.

Regelmässig scheint die Abhängigkeit von der Beleuchtung bei dem Nystagmus der Bergleute ausgesprochen zu sein. - Ich selbst habe niemals nystagmuskranke Bergleute untersucht: die in der Literatur vorhandenen Beschreibungen, insbesondere der neueren französischen Autoren, sind jedoch umfangreich und zahlreich genug, um charakteristische Merkmale anfstellen und mit dem Nystagmus überhaupt vergleichen zu können.

Keiner der bis jetzt beschriebenen Falle von Nystagmus bei Bergleuten liess die erwähnte Abhängigkeit von der Beleuchtung vermissen.

Der Nystagmus findet sich nur bei solchen Arbeitern, die sich den Schädlichkeiten der Grube sehr lange Zeit hindurch ausgesetzt haben. Ich habe die vorhandene Literatur durchsucht und finde, dass die Berglente, welche den Nystagmus zeigen, mindestens 10 bis 12 Jahre, die meisten viel länger, gearbeitet haben. Ich halte diesen Umstand für besonders wichtig. 
Der Nystagmus ist im Beginn der Erkrankung passager, zeigt sich Anfangs nur in der Grube, wenn die Kranken meist bei mangelhafter Beleuchtung der Grubenlampe, auf dem Boden liegen und in gezwungener Körperhaltung gewöhnlich mit emporgerichtetem Blick arbeiten. Bei Unterbrechung der Arbeit hört dann der Nystagmus auf.

Er kann dann meistens durch grelle und plötzliche Beleuchtung auch ausserhalb der Grube wieder hervorgerufen werden (beim Austreten aus der Grube an's Tageslicht, Graefe, Fall 15) und insbesondere, wenn in der Dunkelheit ein heller Gegenstand oder ein brennendes Licht fixirt wird (Schroeter, A. Graefe, Noel, Dransart, v. Reuss). - Die Abhängigkeit ist eine so grosse, dass es in der Regel, um den Nystagmus hervorzurufen, genügt, den Kranken des Abends in ein Zimmer zu führen, in welchem ein Licht brennt. Regelmässig wird nach D ransart der Nystagmus durch die ophthalmoskopische Beleuchtung hervorgerufen, die Augen verhalten sich nach demselben Autor dem farbigen Lichte gegenüber in verschiedener Weise.

Beim Fixiren rother, gelber und gruner Töne tritt der Nystagmus weniger rasch hervor, als beim Fixiren blauer und violetter Pigmente. Die brechbareren Lichtstrahlen scheinèn daher grösseren Reiz zu verursachen.

Mehr als bei den übrigen Formen des Nystagmus zeigt der Nystagmus der Bergleute eine unverkennbare Abhängigkeit von der Einhaltung bestimmter Blickrichrichtungen. Seltener wird der Nystagmus ausschliesslich beim Blick nach unten (Graefe, Fall 16) oder zur Seite hervorgerufen, meistens sind es Erhebungen des Blickes, welche den Nystagmus im Gefolge haben. Bisweilen kann der Nystagmus auch im Dunkeln bei künstlicher Beleuchtung nur hervorgebracht werden nach vorhergehender körperlicher Anstrengung (Graefe, Fall 16), 
oft genügen einige Kopfbewegungen, um ihn hervorzurufen (Dransart*).

Die Kranken Bergleute haben während des Nystagmus die Empfindung von Scheinbewegung. Sie leiden vielfach an Hyperaesthesien oder Anaphäsien und anderen nervösen Symptomen (Graefe, No ël**), Dransart***), die als cerebrale Reizsymtome aufgefasst werden können. Nach Dransart, der allein 13 Fälle genau beschreibt, leiden sebr viele Kranke an allgemeiner Anämie und Schwächezuständen.

Der Nystagmus der Berglente ist, wie jeder andere Nystagmus, auch von Gemüthsbewegungen abhängig; er wird ebenso beeinflusst durch die Wirkung des Alkohols (A. Graefe, Dransart, 1. c.)

Der Nystagmus der Bergleute schwindet fast immer, wenn die Kranken zu arbeiten aufhören.

Der Umstand, dass der Nystagmus überhaupt so oft nach Aenderung der Beleuchtung variirt, scheint für dessen Abhängigkeit von einem centralen, reflectorisch erregbaren Reizvorgang zu sprechen und in den vielen Fällen, bei denen mit Regelmässigkeit durch ein im dunklen Raume brennendes Licht der Nystagmus hervorgerufen wird, muss es sich wohl um eine besonders ausgebildete Reflexerregbarkeit bestimmter Centra handeln, und könnte, von diesem Gesichtspunkte betrachtet, der Nystagmus mit den sog. Reflexneurosen verglichen werdent). Inwiefern eine solche Anschaunng berechtigt ist, werde ich weiter unten zu erläutern versuchen.

*) Dranssart. Annales d'oculist. T. LXXVIII, pag. 114, Jahrgang 1877).

**) Noël, Léon: Nystagmus intermittent, l. c., pag. 201.

***) Dranssart, 1, c., pag. 100 .

f) Anch vom Acusticus aus ist reflectorisch Nystagmus herwor gerufen worden. Vergl pag. 41. 
III. Theorie des Nystagmus.

A. Seitherige Theorien.

Boehm hat bekanntlich den Nystagmus als eine Folge von Muskelkrankheiten aufgefasst. Nach ihm erklärt sich diese Bewegungsanomalie durch die Functionsstörung eines einzigen Augenmuskels, vorzugsweise eines In- oder Externus, welcher entweder zu straff oder zu schlaff gespannt ist, und daher seinem Antagonisten nicht das normale Gegengewicht leistet. Diese gänzlich unphysiologische Theorie Boehm's hat durch Nakonz eine Widerlegung gefunden, welche auch experimentell das Unhaltbare der Boehm'schen Ansicht nachweist.

Nakonz*) glaubt an eine neuropathische Natur des Nystagmus und erklärt ihn als Krampferscheinung, ohne jedoch besondere Beweise oder instructive Beispiele für seine Ansicht beizubringen.

Kugel**) sucht den Grund des Nystagmus in der Behinderung des Erlernens einer genauen Fixation beim Kinde, er macht die Sehstörungen, die sich so oft beim Nystagmus vorfinden, für das Entstehen des letzteren verantwortlich. Obwohl K. sich gegen Nakonz und eine neuropathische Natur des Nystagmus ausspricht, erklärt. er inconsequenter Weise den Nystagmus dennoch als eine Folge "verminderter Reflexaction des nervösen Apparates."

K. glaubt, dass bei Krankheiten des Hintergrundes der Nystagmus sich aus einer Art von Wettstreit zwischen Macula lutea und Netzhautperipherie erklären lasse und fasst diese Falle des Nystagmus daher als besondere Klasse zusammen. Der genannte Autor scheint bei dieser seiner 2. Klasse des Nystagmus in gewissem Grade eine früher schon von A rlt gegebene Definition zu acceptiren,

3) Naronz, l. C.

**) Kuge1, 1. c. 
nach welcher bei Trübungen der brechenden Medien die Bewegungen des Nystagmus rein zum Zwecke der Verbesserung der Sehschwäche, um die Netzhauterregung $\mathrm{zu}$ verstärken, auftreten, und daher denselben Effect hervorbringen sollen, wie wir ihn anch erzielen, wenn wir Gegenstände, welche ein schwaches Auge nicht mehr gut erkennt, in Bewegung versetzen. Abgesehen jedoch von den von Baumeister referirten Fällen, durch welche thatsächlich bewiesen wird, dass der Nystagmus an und für sich die Sehschärfe herabsetzt, ist hier zu beachten, dass die Oscillationen in den meisten Fällen von Nystagmus zu rasch geschehen, als dass man sich den Effect auf die Sehschärfe erklären könnte*).

Ausserdem ist sehr häufig der Nystagmus ererbt und stammt in vielen Fällen, wenn er nicht angeboren ist, doch aus einer so frühen Lebensperiode, dass von einer Erlernung nicht die Rede sein kann.

Insbesondere aber spricht gegen die Arlt'sche Erklärung der Umstand, dass im späteren Leben, bei gelegentlichem Entstehen vollständig gleichwerthiger Sehstörungen in Folge von Hornhantflecken etc. niemals Nystagmus erlernt wird, trotzdem das Mittel wegen seiner Einfachbeit um so leichter gefunden werden müsste.

In eine 3. Klasse bringt Kugel den Nystagmus, welcher zusammen mit einer als ursächlich anfgefassten Insufficienz der recti interni vorkommt.

Auch die übrigen Erklärungen Kugel's bedürfen nach dem, was über die Complication des Nystagmus oben gesagt ist, keiner weiteren Widerlegung.

Gadaud**) unterscheidet zwischen einem symptomatologischen und einem idiopathischen Nystagmus. Der erstere findet sich ausschliesslich bei Gehirnkrankheiten,

*) Man vergl. Aubert, Physiologie der Netzhaut. Wreslau, 1865 , pag. 104.

*) Gadaud, 1. c., pag. 9. 
der letztere wird von G. im Sinne Boehm's auf eine entzündliche Retraction und Verkürzung eines bestimmten Augenmuskels zurückgeführt.

A. Grae fe nimmt in der betreffenden Frage keine entschiedene Stellung ein. Wenn er mit $\mathrm{Kugel}$ die Behinderung der Netzhautfunction zur Zeit „der Erziehung und Festigung einer normal fixirenden Stellung der Augen" besonderen Einfluss zuschreibt, so hält er es doch für sehr wahrscheinlich, dass "eine besondere anomale Muskeldisposition" zum Zustandekommen des Nystagmus erforderlich sei.

Gegen eine myopathische Ursache des Nystagmus spricht nun aber, wie auch schon Nakonz, Boehm gegenüber, hervorhebt, vor Allem der Umstand, dass in allen Fällen, welche nicht mit Paralyse oder Parese eines A ugenmuskels complicirt sind, die Bewegungsexcursionen der Augen nach allen Richtungen hin, vollständig normale Beweglichkeitsverhältnisse voraussetzen, und dass selbst in den Fällen, wo der Nystagmus mit Strabismus combinirt vorkommt, die Beweglichkeit des schielenden Auges, unabhängig vom Binocularsehen geprüft, durchaus keine Defecte zeigt.

Eine Muskelschwäche müsste sich, ebenso wie eine Spannungszunahme, durch Beweglichkeitsdefecte, wenigstens in den Grenzstellungen, verrathen; vor allem aber bei künstlicher Unterbrechung der binocularen Fixation hervortreten. Bèi alternirender Bedeckung der Augen ist nun aber eine latente Insufficienz der Augenmuskeln, wie sie $\mathrm{Kugel}$ bei seiner 3. Gruppe vorfindet, nur sehr selten anzutreffen.

Es ist im Gegentheile sehr auffallend, dass das Muskelgleichgewicht in systematischer Weise unter Pris. men bei künstlicher Diplopie geprüft, bei vielen Nystagmuskranken durchaus normale Verhältnisse erkennen lässt.

Der einfache Nachweis, dass das Muskelgleichgewicht 
in Fällen von Nystagmus normal sein kann, führt zu der Berechtigung, sich von der alten Erklärung des Nystagmus als Coordinationsstörung, vollständig zu emancipiren.

Wenn die Augenbewegungen normal sind, wenn der normale Sehact, wie das die Prismenversuche beweisen, ganz wie im Normalzustande, vorhanden sein kann, so folgt, dass der Nystagmus nicht auf Coordinationsstörung beruht, und überhaupt mit den gewöhnlichen Augenbewegungen gar nichts zu thun hat.

Wie beim einfachen Tremor der Hände etc. alle möglichen Bewegungen gut ausführbar sind, und weder das Zittern diese Bewegungen selbst, noch auch die Vornahme dieser Bewegungen das Zittern wesentlich verändert (natürlich abgesehen von dem sogen. Intentions: zittern Charcot's), so besteht der Nystagmus unabhängig neben den Augenbewegungen, ohne die letzteren zu ändern und ohne auch durch letztere wesentlich verändert $z u$ werden.

Wenn dem Nystagmus also kein Leiden der Augenmuskeln zu Grunde liegt, so wird auch die "Behinderung des Erlernens einer genauen Fixation" direct den Nystag. mus nicht hervorbringen können. Die Festigkeit der normal fixirenden Stellung ist eben in vielen Fällen von Nystagmus ganz unzweifelhaft vorhanden; ausserdem bringt die Behinderung der Fixation, dort wo sie zweifellos hervortritt, und zwar gerade bei offenkundigen Muskelaffectionen wohl Schielstellungeh, aber niemals Nystagmus hervor. - Die mangelhafte Sehschärfe muss daher, wenn ihr ein ursächliches Moment zugeschrieben werden soll, in anderer Weise wirksam sein.

Nach meiner Meinung ist der Nystagmus, wie der Tremor anderer Körpertheile, immer central bedingt; unter gewöhnlichen Verbältnissen ist derselbe passager oder continuirlich auftretend, wie der Tremor als Neurose aufzufassen, selbst wenn man nicht im Stande ist, 
greifbare centrale Störungen nachzuweisen; unter anderen Verhältnissen als wichtiges Symptom vorhandener centraler Anomalien zu betrachten. Den Nystagmus der Bergleute sucht A. Graefe (pag. 235) durch die fast permanente Anstrengung zu erklären, im Dunkeln ge* wisse Objecte deutlich zu erkennen.

A. Bode*) glaubt, dass eine durch die gezwungene Haltung der Bergleute herbeigeführte Uebermüdung bestimmter Muskeln eine Art Bewegungsneurose veranlasse; auf diese Erklärung werde ich weiter unten zurückkommen. Dransart, der letzte französische Beobachter des Nystagmus der Bergleute kommt wieder auf Boehm's Erklärung zurück und sagt: "Le nystagmus des mineurs est une myopathie de la paire des élévateurs et du droit interne intimement liée à l'anémie et à la parésie de l'aecommodation."

Nieden (l. c.) glaubte den Nystagmus der Bergleute im Sinne v. Arlt's erklären zu können, als empirischen Versuch, die Sehschärfe za verbessern. N. glaubt; dass man es mit Hemeralopie za thun habe. Diese Ansicht ist schon von A. Graefe widerlegt worden.

v. Reuss (l. c.) stellt eine rein toxische Wirkung der Grubenluft als ursächlich hin und auch A. Graefe schreibt den hygienischen Verhältnissen, unter welchen die Bergleute arbeiten, einen besonderen Einfluss zu.

Die meiste Wahrscheinlichkeit hat die Erklärung Bode's für sich, welche auch in der Graefe'schen Arbeit angeführt, pag. 235 aber fallen gelassen wird, weil mehrere unter den an Nystagmus leidenden Bergleuten nie unter den genannten erschwerenden Verhältnissen gearbeitet hatten. Wenn aber auch einzelne Fälle vorkommen, bei denen die tägliche Arbeit jene stark forcirte Blickrichtung nach oben bei auch sonst gezwungener

*) A. Bode, Dissertation. Halle 1874. 
Körperhaltung nicht fordert, so findet sich doch in den meisten aller referirten Fälle von den Autoren besonders betont, dass die Kranken unter jenen Umständen stets gearbeitet haben. Nun geht aber aus den Angaben der Literatur hervor, dass die afficirten Bergleute sämmtlich lange Jahre gearbeitet haben müssen, also jenen Schädlichkeiten dauernd ausgesetzt waren, bevor die Störung eintritt, und dass diese Störung anfangs nachlässt, sobald die Arbeit unterbrochen wird.

Es ist also mindestens wahrscheinlich, dass eine Ueberwindung bestimmter Muskelgruppen den Nystagmus der Bergleute mit bedingt; um denselben jedoch zur Ausbildung zu bringen, sind die von Dransart so sehr betonten Complicationen, die Anämien etc. wohl nicht olne Bedeutung.

In der Nervenpathologie hat der Nystagmus der Bergleute zahlreiche Analogien. Die Symptomatologie des Schreibekrampfes z. B. hat vielfache Aehnlichkeit. Die Bewegungen der Hand, der Finger, sind nach allen Richtungen möglich, nur bei einer bestimmten Bewegung, bei welcher so und so viele Muskelgruppen in genauem Verhältnisse betheiligt sind, tritt der Krampf ein, in ausgebildeten Fällen genügt es schon, um ihn hervorzubringen, die Hand in besonderer Weise zu legen, ohne den Versuch des Schreibens zu machen.

Man mache nach einer kräftigen Anstrengung der Muskulatur des Armes einige Male forcirte Pronations- und Lupinationsbewegungen des Vorderarmes, oder forcirte Flexionen der Hand - ein bemerkbares Zittern wird nicht ausbleiben, wenn nach einer kleinen Ruhepause diese Be. wegungen langsam wiederholt werden. Aber dieses Zittern wird nur bei denselben Stellungen auftreten oder sich doch beträchtlich verstärken, die wir zuvor mit besonderer Kraft zuwege gebracht haben. Aber auf Uebermüdung allein beruht weder der Tremor der 
übrigen Körpermuskulatur, noch der Nystagmus am Auge. Es ist aus der Experimentalphysiologie bekannt, dass, wenn der Nerv eines ermüdeten Muskels gereizt wird und die Stromstärke bis zur folgenden Contraction des Muskels ansteigt, keine Stromstärke gefunden wird, bei welcher Zittern beobachtet würde.

Es muss also zu der Uebermüdung der bestimmten Hebemuskeln des Auges, welche bei dem Nystagmus der Bergleute in den meisten Fällen zunächst betheiligt sind, noch ein anderes, bisher unbekanntes Moment hinzukommen, um die zitternden Bewegungen der Bulbi beim Blick nach oben zu erklären.

B. Ueber die Bedeutung des Muskeltonus für Genese des Nystagmus.

Das Auge ist wohl das beweglichste Organ des menschlichen Körpers; seine Muskeln nach Mass und Gewicht relativ zu der Kleinheit des Organs, wohl auch die grössten.

Entsprechend dieser entwickelten Muskulatur ist ein Nervenreichthum vorhanden, der sich auch wohl an keinem anderen Körpermuskel wiederfindet; die dicken, in jeden einzelnen Muskel eintretenden Nervenzweige verästeln sich ungemein reichhaltig, was man auch an makroskopischen Augenmuskelpräparaten ganz gut sieht. Die erwähnten anatomischen Verhältnisse sind wohl mit Rücksicht auf die hohe physiologische Funktion so ausgebildete, denn von anderen Organen ist ein so genaues coordinirtes Zusammenwirken nicht gefordert, wie es bei den beiden Augen thatsächlich ausgebildet ist.

Nach A. W. Volkmann's*) Messungen sind rectus

*) Volkmann, A. W. Zur Mechanik der Augenmuskeln. (Berichte der Königl. Säehs. Gesellschaft der Wissenschaften, Math. Physik. Klasse 1869.) 
internus und externus die schwersten Augenmuskeln; die obliqui die leichteste. Die Contractilität dagegen ist beim obliquus inferior und dann beim abducens am grössten, beim rectus internus am geringsten.

Wie die übrigen Körpermuskeln, so werden auch die sämmtlichen Augenmuskeln während des Lebens auch im Zustande der Ruhe dauernd innervirt.

J. Mueller hat die Lohre vom Muskeltonus zuerst aufgestellt; nach ihm befinden sich sämmtliche Körpermuskeln beständig in einem Zustande schwacher Contraction, bedingt durch eine rom Rückenmark ausgehende unwillkürliche schwache Erregung der motorischen Nerven.

Hermann und Cohnstein betrachten den Yuskeltonus als eine Refiexerscheinung, bedingt durch dauernde Erregung sensibler Nerven.*)

Ob diese Innervation variiren kann, ist nicht bekannt; hört dieselbe auf, wie in Fällen von Lähmung sämmtlicher Augenmusseln, so giebt sich die folgende Erschlaffung der Muskulatur durch Vortreten des Bulbus kund.

Diese fortdauernde Innervation, die stetig von den Centralorganen aus auf die Muskeln ausströmt, ist von den Willensreizen, welche die zweckmässigen Augenbewegungen vermitteln, durchaus unabhängig und verschieden. Sie ist im Normalzustande regelmässig auf die Muskulatur des Auges vertheilt, so dass das Auge in gewisserdurch den Tonus seinersämmtlichen Muskeln bestimmten Gleichgewichtslage ruht.

Ist aber die rom Centrum ausgehende Innervation ungleichmässig vertheilt oder erfolgen die Innervationen nicht continuirlich, sondern unterbrochen, so wird es zu einer tonischen Zusammenziehung der betheiligten Mus-

*) Vergleỉche darüber Leyden, Klinik der Rückenmarkskrankheiten, Bd.I, pag. 60, Berlin, 1874. 
keln gar nicht kommen können und es werden leichte klonische Zuckungen den leichten unterbrochenen Nervenreizen entsprechen. So wäre das Zittern des Augapfels, der Nystagmus, als eine Anomalie des A ugenmuskeltonus $z \mathfrak{u}$ betrachten.

Mit der vorstehend entwickelten Theorie sind sämmtliche Thatsachen so sehr im Einklange, dass ich dieselbe zu vertreten keinen Anstand nehme.

Zunächst ist klar, dass bei dem Nystagmus, von diesem Standpunkte betrachtet, die Beweglichkeit der Augen und der binoculare Sehakt normal sein kann.

Es ist wohl gegenwärtig zweifellos, dass bei den Willkürbewegungen der Angen nicht blos ein einzelner Muskel, oder ein Muskelpaar, sondern sămmtliche Muskeln innervirt, resp. in ihrer Innervation verändert werden. Schon Ruete hat diese Meinung geäussert; dieselbe wird von Duchenne und Volkmann vertreten.

Wenn also eine Intention zu einer bestimmten Bewegung vorliegt, so muss zu. der Innervationsgrösse, welche den Tonus nnterhält, eiue bestimmte der Willkür entsprechende Innervationsdosis hinzukommen, und die letztere wird eine vollständig coordinirte Muskeithätigkeit beiderseits veranlassen, es versteht sich von selbst, dass eine etwaige Unregelmässigkeit der den Tonus bewirkenden Innervation dabei bestehen bleibt, oder mit anderen Worten, es kann während und nach der Willkürbewegung ein im Ruhezustande vorhandener Nystagmus unverändert andauern.

Inwiefern der Nystagmus dieser Auffassung abhängig wird, von dem oben definirten Einflusse körperlicher Anstrengungen, Gemüthsbewegungen etc., ist vorläufig ebensowenig, als der Einfluss derselben Momente für den Tremor zu erklären. Nur wäre auch hier auf den Umstand hinzuweisen, dass gerade dieselben Einflüsse das Verhalten des experimentell besser studirten Gefäss- 
tonus bedingen, weleh' letzterem bekanntlich für das Auftreten des Tremor eine besondere Bedeutung zukommt.

Ueber den Sitz der Centralstätte, von welcher die den Nystagmus bedingende Innervation ausgeht, kann man bis anf weiteres nur Vermuthungen hegen. Ob derselbe identiseh ist mit dem Coordinationscentrum für die Augenbewegungen, bleibt dahingestellt, für ein solches Verbältniss sprechen jedenfalls die Beobachtungen von willkürlichem Nystagmus. - Wie sich die Vierhügel, welche nach Adamü $\mathrm{k}^{\prime} \mathrm{s}^{*}$ ) Versuchen als Coordinationscentrum anzusprechen sind, dem Nystagmus gegenüber verhalten, ist unbekannt; zwar ruft nach A da mük gleichzeitige Reizung der beiden vorderen Vierbügel nystagmusartige Bewegungen hervor***), doch sind Erkrankungen der Vierhügel fast regelmässig mit Amaurose(W.W agner***),

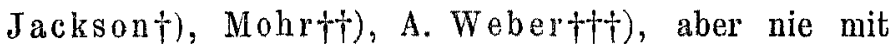
Nystagmus complicirt gefunden worden (Steffen ${ }^{*}+$ ). Dagegen geht aus den von mir referirten eigenen und fremden Beobachtungen, sowie aus den Resultaten des Experimentes an Thieren soviel mit Bestimmtheit hervor, dass vornehmlich die Gegend des Bodens des 4 . Ventrikels, dann des Streifenhügels etc., in letzterer Beziehung von grösster Bedeutung sind.

Die Abhängigkeit des Nystagmus von der Beleuchtung ist nur auf dem Wege des Reflexes zu erklären. Es werden die sensiblen Reize (vom Sehnerven aus) auf den

*) Adamük, Centralblatt 1870.

**) Man vergl. L onget. Anatomie und Physiologie des Nervensystems, ibersetzt von Hein. Leipzig 1847 , pag. 349.

***) Klinische Monatsblätter füx Augenteilkunde, Bd. 1864, p. 44.

t)

$+\div$

$++t$

,

$" \quad "$

Bd.1865, p. 103.

"f) Steffen (Tuberculose der corpora quadrigemia. Berlin, klin. Wochenschrift, 1864). 
Nystagmus ganz ebenso einwirken können, wie auf den Muskeltonus überhaupt, der nach Herrmann durch dauernde Erregung sensibler Nerven reflectorisch bedingt ist.

Die Abhängigkeit des Nystagmus vom binocularen Sehakt lässt ferner vermuthen, dass es bisweilen auf die beiderseitige Netzhauterregung ankömmt.

Die Bedeutung vorhandener Sehschwäche für die Entstehung des Nystagmus ist oben des Näheren gewürdigt worden; es kann nicht geleugnet werden, dass für manche Fälle diese Bedeutung zu Rechte besteht, ob aber die undeutlichen Netzhautbilder zu einer ,verminderten Reflexaction von Seiten des nervösen Apparates" jemals Veranlassung geben können, ist mehr als zweifelhaft.

Wenn der Umstand, dass der Nystagmus gewöhnlich beiderseits ausgebildet ist, für die Annahme spricht, dass die ursächliche Innervationsanomalie funktionell von einem bestimmten Centraltheile bedingt, auf beide Augen gleichmässig wirkt, so sprechen die von $A$. Graefe und Dransart referirten Fälle, bei welchen die Nystagmusbewegungen sich auf beiden Augen ungleich, bisweilen gänzlich, entgegengesetzt verhielten, dafür, dass die Einwirkung auch ungleichmässig stattfinden kann. Endlich beweisen die Fälle von rein einseitigem Nystagmus, dass diese Innervationsanomalie auch nur die Muskelgruppen des einen Auges unabhängig vom anderen treffen kann; diese letztere Thatsache ist, nachdem feststeht*), dass rein einseitige Augenbewegungen als ganz physiologische Erscheinung während des natürlichen Schlafes vorkommen, mit den Thatsachen völlig im Einklange.

*) Vergl. Raehlmann und Witkowski (Ueber atypische Augenbewegungen, 1. c.) 